Revista de la red interuniversitaria de estudios sobre las literaturas rioplatenses contemporáneas en Francia

Hors-série | 2019

Ricardo Piglia: Cierta idea de literatura

\title{
El último viaje de Orfeo: Los diarios de Emilio Renzi
}

Teresa Orecchia Havas

URL: http://journals.openedition.org/lirico/7921

DOI: $10.4000 /$ lirico.7921

ISSN: 2262-8339

Editor

Réseau interuniversitaire d'étude des littératures contemporaines du Río de la Plata

Referencia electrónica

Teresa Orecchia Havas, «El último viaje de Orfeo: Los diarios de Emilio Renzi », Cuadernos LIRICO [En línea], Hors-série | 2019, Puesto en línea el 16 febrero 2019, consultado el 09 mayo 2019. URL : http:// journals.openedition.org/lirico/7921 ; DOI : 10.4000/lirico.7921

Este documento fue generado automáticamente el 9 mayo 2019.

\section{(c) (1) $\Theta \Theta$}

Cuadernos LIRICO está distribuido bajo una Licencia Creative Commons Atribución-NoComercialSinDerivar 4.0 Internacional. 


\title{
El último viaje de Orfeo: Los diarios de Emilio Renzi
}

\author{
Teresa Orecchia Havas
}

Ricardo Piglia Papers (C1513); Manuscripts Division, Department of Rare Books and Special Collections, Princeton University Library

“[L]e problème [...], pour un écrivain, n'est pas d'être "éternel" (définition mythologique du "grand écrivain"), mais d'être désirable après sa mort."

R. Barthes

\section{Lo póstumo, lo inédito. Una nota sobre edición, estética y poética}

1 La categoría de lo póstumo goza de una renovada notoriedad contemporánea tanto europea como latinoamericana, cuyas diversas razones, editoriales o hermenéuticas, requerirían un debate más amplio que estas notas. Sólo quisiera apuntar aquí, a modo de comienzo, la tensión con la idea de "inédito" que se sobreentiende en la semántica de lo "póstumo" y el carácter original de los diarios publicados de Ricardo Piglia en relación con ambos conceptos.

2 En las últimas décadas del siglo XX y en lo que va del XXI, al visible interés filológico o editorial por lo póstumo entendido como inédito y de lo inédito como posible contracanto, extensión o reversión de la obra publicada, se ha sumado el entusiasmo por los escritos personales o íntimos, las correspondencias, las notas de carnet y demás vías de exploración de la subjetividad y de la génesis de la creación, que en ciertos casos fueron incluso consideradas como superiores en interés testimonial y en valor literario a la obra consagrada de éste o aquel escritor. La sola literatura europea, por ejemplo, es pródiga en importantes publicaciones póstumas de escritos personales procedentes de archivos $^{1}$, pero también ofrece datos sobre aquello "póstumo" que repite, de una forma u otra, lo ya publicado², así como de lo "póstumo" preparado en vida por el autor y 
destinado a ser dado tal cual a la imprenta, o por lo contrario, incluye el caso de notas y diarios considerados por sus autores como materiales del todo diferentes a la obra y archivados en consecuencia ${ }^{3}$. Evidentemente, el ámbito hispanoamericano cuenta con sus ejemplos propios, discutidos, insólitos o previsibles, desde la edición de los diarios de Alejandra Pizarnik hasta la de los papeles de Rodolfo Walsh, pasando por la particular estrategia combinatoria de Arguedas en sus Zorro (s), los diarios inventados de Mario Levrero o la aventura de los de Idea Vilariño, vueltos a copiar y expurgados por ella misma a efectos de una publicación futura largamente diferida.

3 La cuestión tiene entonces contornos problemáticos ${ }^{4}$ que se acentúan con un cariz propio en el caso de Ricardo Piglia. El diario que el escritor lleva señaladamente desde su adolescencia, aludido o anunciado en sus diálogos con terceros a lo largo de varias décadas, algunos de cuyos fragmentos habrían sido incluidos en textos de ficción o de reflexión ensayística ${ }^{5}$, es copiado y reorganizado por él mismo durante sus tres últimos años de vida, y se publica en parte en esos mismos años (vol. I, 2015; vol. II, 2016), y en parte unos meses después de su muerte (vol. III, 2017). La revisión y copia definitiva de los originales, que según los Diarios se iniciaría en marzo de 2014 (III, 9), está sin embargo mencionada desde antes en diversas intervenciones del autor, con frecuencia intensificada desde que deja de enseñar en Princeton en 2010-2011.

Por otra parte, en el primer semestre de 2011 se publican, a manera de anticipo, simultáneamente en Buenos Aires (Revista $\tilde{N}$ ) y en España (Babelia), una serie de textos que luego se podrán leer en la sección final («Días sin fecha») del tercer volumen de los Diarios $^{6}$. Poco más tarde, entre 2012 y 2015, y como en la serie anterior, precediendo o acompañando una edición o reedición, se insertan en la prensa varios otros fragmentos entresacados de diferentes momentos del diario ${ }^{7}$. Pero su función anunciadora de un texto $u$ otro de pronta aparición se ve subrayada en ciertos casos por el agregado de un párrafo que actualiza la enunciación. Esas líneas llevan al lector al presente y a la condición de Piglia/Renzi en el momento de copia definitiva de los cuadernos (como lo harán por su lado los Diarios). Si se coteja la edición en libro con esas entregas parciales se perciben en éstas dos pautas principales de encuadre: un protocolo de presentación de una publicación inminente o futura, enfatizado a veces por un dispositivo que actualiza el discurso, y un procedimiento de montaje de fragmentos ordenados en torno a situaciones o tópicos. Esta operación, acompañada por la tracción enunciativa hacia el presente, facilita la inserción de páginas sin fecha precisa y que podrían haber sido escritas con mayor, menor o total independencia del diario original (como lo son también las que compondrán los "Días sin fecha" en la edición definitiva). Es evidente entonces que, junto con la preparación de la edición por el autor y la particular cronología de ésta, todas esas publicaciones previas ponen en cuestión la condición "póstuma" de los Diarios, al menos si se la entiende de manera estricta. Desde un punto de vista externo, las entregas de prensa obedecen a una estrategia semejante a la de las bonnes feuilles, con la que juegan sagazmente, adaptando incluso las inserciones a la satisfacción de un suspenso serial (caso de los textos de 2011), o al constante respaldo de la construcción de una figura de autor (passim).

5 En tercer lugar, y a diferencia de los diarios fehacientemente "póstumos", los de Piglia incluyen en sus tres volúmenes y en particular en el primero, una serie de viejos y nuevos textos (cuentos o ensayos ya publicados, capítulos introductorios de sección, etc.), elaborados o bien retrabajados coetáneamente a la reescritura y copia de los famosos cuadernos originales y destinados in fine a formar una unidad con éstos. 
6 Los Diarios se presentan por lo tanto como el resultado de un proceso complejo donde alternan al menos tres estrategias: la selección puntual de materiales preexistentes y su reescritura, es decir, un procedimiento de compresión y corrección combinadas; la supresión (posible) de amplias zonas de material, puesto que las anotaciones ordenadas por años no llegan más que hasta 1982; y por fin, el agregado de materiales diversos en el momento de su preparación en volumen, una actividad de expansión que apunta sobre todo a enunciar con acento puesto en el presente. Tomados en su conjunto y según la evidencia textual externa, que concierne las prepublicaciones, la publicación y la estructura de los volúmenes, los Diarios serían entonces algo así como una obra cuasi-póstuma, un centón orgánico (planeado, ordenado, representativo, sintético) de una escritura mucho más extendida y forzosamente inédita, a la que se han agregado páginas diversas en el momento de su preparación en volumen ${ }^{8}$.

7 El tema implica sin embargo una problemática más amplia, esencial en la poética de este escritor. Si la obra narrativa de Piglia se construye en general lentamente -los Diarios dan abundante cuenta de largos períodos de elaboración-, la mayor parte de los cuentos, notas críticas y ensayísticas, así como algunos capítulos de las novelas publicadas suelen reaparecer en volúmenes que proponen recomposiciones de lo ya impreso, sugiriendo otras lecturas a partir de nuevos encuadres o de modificaciones parciales de los textos. Piglia reescribe, se corrige, introduce cambios mínimos o fundamentales, recontextualiza, "edita" una y otra vez los textos, entregándose a una incesante tarea de relectura de su propia obra, visible en esas prácticas de montaje y recomposición que, si fueron quizás aprendidas en Borges, pueden recordar incluso a las que son corrientes en las recopilaciones de poesía?.

8 No es fácil entonces pensar lo editado y lo inédito contraponiéndolos como opuestos; son más bien versiones de una topografía cambiante, de un corpus siempre en movimiento y transformación, de una concepción de la literatura que acerca el escribir al componer (musicalmente), el crear al interpretar (una partitura secreta), el publicar al "editar" (o sea, cortar y montar) o aun al reeditar, burlando la "superstición" del texto original o definitivo. De modo semejante, la habitual práctica de reescritura de las entrevistas, con su vaivén entre lo oral y lo (muy) escrito, tanto como los anuncios frecuentes sobre la(s) obra(s) futura(s), fieles o no al estado real de ciertos proyectos, más allá de ser apoyos de una estrategia autoral, forman parte de esta peculiar manera de concebir el trabajo literario como si se operara en un espacio de hibridaciones reversibles, continuo e intermitente a la vez, constantemente transformable o perfectible, que propone siempre la imagen de un libro por venir y lucha obstinadamente con la fijeza de las cesuras temporales.

9 La misma ética experimental, la misma poética de la reescritura y la circulación de enunciados, planteada ahora con otros alcances, conduce las operaciones que realiza Piglia sobre sus cuadernos originales, dejando huellas visibles y otras fuertemente conjeturables en muchos pasajes de los Diarios. La alternancia presente/pasado en cantidad de páginas, los capítulos referidos a un presente de escritura que es el de la composición de los volúmenes, la estructura de éstos orientada a una lectura interpretativa o alegórica (como ya ocurría con Nombre falso y Prisión perpetua, sus libros de relatos más auto-reflexivos), forman parte del mismo gesto inicial: esquivar la trampa de las formas encerradas en la cronología, desafiar la lógica de la vida que cierra la escritura con la muerte, pensar la literatura como una forma material que no conoce su fin. 


\section{¿Qué Diario es ése?}

10 personaje de papel son las marcas más ostensibles de esa voluntad de hacer literatura, que no por esperable resulta menos sorprendente aquí en tanto transformación de un género. Dos líneas convergen en Los diarios de Emilio Renzi al servicio de aquel privilegio otorgado desde siempre a la escritura, que ocupa el centro de las ficciones de Piglia, inspira su pensamiento crítico y define su imagen personal. Por un lado, el diario se propone como parte de la obra literaria, suerte de coronamiento o mot de la fin de la obra publicada, al tiempo que se lo ausculta como "dépôt d'être", o gaje de entidad de un sujeto contra el anonimato y la in-existencia, escritura de una trayectoria o de un lugar intelectual. Por otro, los Diarios vuelven sobre una imagen fantasmática de la enunciación que la asocia a la voz de un muerto, rastreable en los textos de Piglia mucho antes del período de redacción definitiva de los tres volúmenes, pero asentada en éste sobre la inesperada y real proximidad de la muerte.

11 La tradición crítica sobre el género del diario permite recordar puntos de partida sobre los que se destaca aún más la especificidad del experimento de Piglia. El eventual carácter literario de los diarios íntimos, así como los problemas de la relación entre la obra y el diario de un escritor, o de la tensión entre el sujeto que escribe y la anotación de la vida han sido abordados en una serie de textos teóricos. Para autores como Barthes, en la estela de cierta tradición francesa reticente ante el carácter sentimental de muchas escrituras personales, la escritura narrativa de lo íntimo puede conducir a la falsificación literaria, ya que el azar y lo efímero de la experiencia no se corresponden con esa retórica; el diario le parece a Barthes inesencial, inauténtico, carente de misión, el estatuto literario de su escritura sería incierto (1993). Para cernir al sujeto habría que poder hacerse eco de su fragmentariedad, elaborar una escritura de la emoción, del decir y no del contar, como la que él mismo practicará a la muerte de su madre (2009). Sin embargo, el crítico rescata el Journal de Gide, porque en su caso se da forma a una totalidad, a un ensemble créatif Vida/ Obra: "[L]a obra no es de las más grandes, la vida no es en absoluto heroica [...], pero se la presenta al lector como dirigida integralmente a la constitución de la obra" (2003: 278; mi traducción) ${ }^{10}$. Así, Gide no resulta un mero testigo (se atenúa aquí el aporte testamentario o memorial de los diarios, sujeto a polémica), sino un "actor de escritura" (278).

Entre los críticos-escritores interesados en el género, se encuentra una posición igualmente distanciada en Maurice Blanchot, quien parte de una argumentación filosófica sobre la índole impersonal del lenguaje y la relación entre abstracción y subjetividad. Blanchot aborda también la obsesión de la nota cotidiana, cláusula tiránica rectora de la aparente libertad estilística del diario, y considera a éste como una forma engañosa e híbrida (1971: 271-279), aun cuando tal juicio no le impide escribir hermosas páginas sobre la escritura personal de Kafka, por ejemplo (1973: 59-98).

13 La compleja relación triangular entre la vida, el lenguaje, el estilo de notación de los diarios íntimos y la estetización literaria que discuten esos autores tiene ecos que se leen en los textos de Piglia. Muchas veces, a lo largo de años, los Diarios de Renzi abordan esta problemática, a comenzar por sus reflexiones en torno a la cuestión de la multiplicidad inorgánica de la vida: "[La vida es una] [D]esordenada secuencia de pequeños acontecimientos», de «acciones mínimas, casi invisibles, cuyo sentido justamente 
depende de la variedad y el desorden de la experiencia» (II, 13); “ Siempre habrá un hiato insalvable entre el ver y el decir, entre la vida y la literatura" (II, 22). El punto estaba ya planteado en la entrada "Difracción" del "Diario de un loco", que reaparece en el tercer volumen: "Difracción. Forma que adquiere la vida al ser narrada en un diario personal. En óptica, fenómeno característico de las propiedades ondulatorias de la materia" (III, 196). Lo inasible de la vida (“CCómo definir la vida real?”, II, 57) y la trivialidad de la experiencia cotidiana vuelven la escritura imposible (I, 122). Consecuentemente, cuanto más inasible resulta la experiencia y menos fidedigna la supuesta unidad del yo, que el autor desestima con igual contundencia (II, 8), más explícito es el recurso a una tercera persona que distancia la posición subjetiva y evita el escollo de la exposición descontrolada o engañosa de la primera. Piglia comenta repetidas veces, en entradas metaliterarias redactadas con su habitual estilo de síntesis pedagógica, ese problema del enmascaramiento del sujeto y de la retórica del género aludiendo a las mismas ecuaciones sobre las que especula la literatura teórica: relato-confesión / narración-mostración / impersonalidad del código lingüístico-lenguaje de la subjetividad / retórica literariaestilo sin cualidades. La búsqueda de un lenguaje no narrativo, por ejemplo, está indicada tempranamente y ligada a la idea de la escritura imposible de los hechos: "Un diario tendría que estar conectado con la segunda parte de la frase ["lo que no se puede ni decir ni hacer"]" (I, 184). La escritura del diario no se identifica con la narración; en ella debe brillar la intransitividad del lenguaje:

Precisamente porque en estos cuadernos no me encuentro a mí mismo sino a ratos, debo valorar su escritura. Escribir un diario es escribir para nadie, un lenguaje cifrado que sólo entiende quien lo ha escrito, no tengo por qué contarme a mí mismo lo que ya sé, nunca explicar: eso no es narrar, sino escribir. Y, a la vez, escribir como si el verbo fuera intransitivo. (III, 31)

Así, la cuestión del sujeto se resolverá en estas notas en favor de la tercera persona, que procura la máscara necesaria al extrañamiento de lo testimonial y protagoniza una enunciación distanciada. El procedimiento conduce hacia el reivindicado hibridismo con lo ficcional; la anotación entra en literatura:

En mi caso podría decir: he entrado en mi autobiografía cuando he podido vivir en tercera persona. (I, 189)

No me reconozco del todo en el individuo que escribe ahí [en viejos papeles] ciertos hechos de mi vida. Ésa es la paradoja, es mi vida, digamos así, pero no soy yo el que la escribe. En ese punto incierto está lo mejor de mi literatura. [Subrayado mío] [...] Esa enunciación -vamos a llamarla así- es lo que justificaría publicar una selección de estos escritos. El material es verdadero, es la experiencia real, pero el que escribe el que habla- no existe. Así defino yo la ficción: todo es o puede ser verdad, pero la clave del procedimiento es que quien narra es un sujeto imaginario. (II, 373)

Piglia es un intelectual preocupado por la ética y las ideologías políticas; la cuestión del lenguaje de la experiencia, abordada en diferentes escritos suyos, primero tras la huella de Benjamin, luego de Brecht, luego en consideraciones sobre la ética de la lectura, ha sido comentada por muchos de sus críticos ${ }^{11}$. En los apuntes de 1980, aquel mismo tema de la escritura intransitiva, abonado por sus lecturas filosóficas de la época, se amplifica y se flexiona hacia la idea de experiencia ética. Según estas páginas del diario, la narración puede en definitiva llegar a evocar la experiencia, pero sólo en tanto sea (o se la formule como) de otros; el sentido de lo vivido sería una zona esencial opaca para el que lo protagoniza; sólo la ficción puede traducirla. Así, el valor ético de la experiencia queda depositado en aquella forma -la ficción- que precisamente trabaja enmascarando a los sujetos y desplazando los sentidos. El lazo conflictivo entre el yo, el mundo y el código se 
ha deslizado desde la anotación a la ficción, desde el testimonio de sí (o la confesión) a los hechos de "él", y desde la presunción de un sentido de lo personal a la afirmación de una verdad de lo impersonal o de una traslación de lo personal a la lengua del otro mediante un proceso de estetización. La literatura resulta de este modo la depositaria de la ética de la significación ${ }^{12}$.

Aquello sobre lo cual hay que callar es la experiencia ética; el significado de la vida no puede ser expresado con el lenguaje de los hechos (en ese espacio se ubica la ficción y especialmente la novela como género post-trágico). Sólo podemos nombrar las cosas que les ocurren a otras personas, nuestra propia experiencia vivida, nuestra existencia, nuestra sensación del paso del tiempo están demasiado próximas a nosotros como para ser visibles de un modo externo (de ahí la imposibilidad y fascinación de los diarios personales como éste); ese mundo constituye el objeto preferente de la novela, la narración coincide con la evocación de esas experiencias incomparables. Sólo se pueden mostrar -en el sentido de Wittgenstein, pero también de Henry James- porque la experiencia vivida es incomunicable. De allí la premisa de Brecht, vivir en tercera persona. (III, 131)

\section{Estrategias y operaciones: hacia la literatura}

17 A lo largo de los años, en sus entrevistas y diálogos, Piglia afirma repetidas veces que lleva un diario personal iniciado ya en su primera juventud, que una vez publicado vendrá a justificar toda su obra precedente. En el diario mismo, en cambio, se lee: "Publicó algunos libros -y publicará quizás algunos más- sólo para justificar esa escritura [del diario]” (I, 11). Y también: "Yo escribo en estos cuadernos porque confío en que alguna vez tendrá sentido pasarlos a máquina y hacerlos publicar, porque yo habré justificado con mi obra la lectura de estos apuntes diarios y personales." (II, 212) Si bien ambas aserciones apuntan a ese conjunto creativo vida-obra del que hablaba Barthes, mientras la primera sugiere que la mejor escritura se sitúa en el futuro, la segunda subraya que sólo la obra autorizaría la escritura de una vida (de escritor). Se trata entonces de una suerte de autorización reversible y a venir de una escritura que va de un registro a otro. El problema de publicar el diario "sin traicionar[lo]", pero ateniéndose a una forma literaria que lo vuelva legible ("un editing del propio autor"), del que habla Piglia a principios de la década (Larre Borges y Bajter 2011: 127-128), ya antes del testimonio filmado por Di Tella, coincide con la presunción de que el diario funcione como el coronamiento de una vida enteramente dedicada a la literatura y que remita a la obra, pero siendo parte de ella. Es decir, que sea el resultado de un proyecto, que se lo lea como una forma diferente de la escritura espontánea, que se lo separe de lo confesional tanto como de lo puramente memorial. En esa medida, el diario no debería leerse como póstumo o testamentario, y se entiende que el objetivo explícito sea lograr publicarlo en vida, "darle toda mi vida a un personaje de ficción" (127).

\section{El diario como construcción}

Pero "editar" el diario supone leerlo, releerlo y copiarlo, muy probablemente más de una vez. La necesidad de copiarlo es uno de los propósitos que reaparece de manera insistente, si no obsesiva, en la boca y la pluma del autor. El tema tiene una declinación dolorosa en los años cercanos al final (III, 159-160), pero está presente en intervenciones anteriores $\mathrm{y}$, a menudo, en el diario mismo: 
Leo fragmentos del diario de Enrique Wernicke en Crisis. De inmediato me propongo "mejorar" estos cuadernos, escribirlos y no reducir todo a estas notas esporádicas. (II, 406)

Empiezo a copiar a máquina mi diario I (1957-1962), ¿para qué? Es imposible que se pueda publicar. (II, 410)

Transcribir el diario sería escribir mi versión de En busca del tiempo perdido. (III, 154)

Naturalmente, la copia de un texto previo no es más que uno de los procedimientos habituales en la escritura de Piglia, generosa en el montaje de fragmentos y en la circulación de textos enteros en diferentes marcos. A través de la repetición y la diseminación de formas, de la apropiación de enunciados, de las variaciones a partir de un motivo, su literatura expone regularmente su vocación experimental, que es también gusto de un juego de inteligencia detectivesca con el lector ${ }^{13}$. Pero esta vez lo que se arriesga es diferente, porque el original que pasará por un proceso de montaje es un diario íntimo, un tipo de texto regido por una pauta de inmediatez y supuestamente adosado a la experiencia de quien lo firma. En principio, el diario habría podido publicarse como tal, aun habiendo sido expurgado o reescrito; habría podido ser sometido a un proceso de poetización o de ficcionalización parcial; habría podido constituirse como novela (la "novela del diario", III, 162; "el libro sobre el diario", II, 352). Todas esas opciones parecen haber sido examinadas por Piglia, que las indica tanto en algunos pasajes de la obra como fuera de ella.

Se ha dicho sin embargo (Di Tella en Garzón 2015) que Piglia consultaba y reescribía la última versión de los diarios en desorden, lo que sugeriría que el ordenamiento definitivo de los tomos publicados es el resultado de un proceso más o menos azaroso de montaje. La afirmación parece discutible a la vista del resultado, pero no deja de inducir la imagen de una suerte de construcción espontánea de los Diarios, un pattern subyacente, como si de todos modos obedecieran a una unidad secreta, a un principio de síntesis que habría actuado por debajo o por encima de las operaciones específicas a las que la reescritura sometía a los originales.

21 En todo caso, si el sujeto que escribe lo hace recuperando fragmentos, éstos aparecen presentados con una coherencia que no debe nada al azar. Al contrario, los Diarios exhiben su carácter de construcción; piden ser leídos como conjuntos complejos, y también como ejercicios de laboratorio, como anotaciones puntuales. El comentario autoreflexivo y metaliterario que involucra la fabricación misma de un registro personal, sus objetivos e incertidumbres, se lee frecuentemente en sus páginas (passim). Al final del primer tomo, se prepara incluso al lector para la continuación del diario. Renzi anuncia a su interlocutor la segunda parte, "Los años felices de mi vida, que van de 1968 a 1975", porque "en esos cuadernos hay muchas historias" (I, 358). En el último tomo, se dirige la lectura aún más lejos, hacia lo que habría sido el plan definitivo de composición:

No podía viajar impunemente -como un sonámbulo- en la máquina del tiempo de sus cuadernos personales, recorriendo los días de su vida, o mejor, de las notas escritas febrilmente con el objetivo de registrar su experiencia. Entonces decidió detenerse en ese primer ciclo que revelaba mejor que nada la verdad de su destino, que hacía ver su proyecto de convertirse en un buen escritor; le había llevado veinticinco años encontrar una salida, una puerta estrecha por donde pasaba, por decirlo así, el sentido. (III, 160-161)

22 La elección de un armazón visible ya desde la organización externa de los volúmenes responde así explícitamente a una exposición donde la vida del sujeto se ordena como una novela de aprendizaje, sobre el eje a la vez temporal y sentimental de los años juveniles (I), seguidos de la época de logros intelectuales (II), y culmina, sin cerrarse, una vez 
alcanzado el triunfo literario (III). Pero esta línea está fraccionada en todos los casos por las frecuentes variaciones sobre el estilo de anotación y por los experimentos con el tiempo cronológico -como el juego que consiste en presentar el año 1962 muy brevemente y en retro-notación (I, 122-134), signo probable de lagunas o de censura en el cuaderno original-. Igualmente son factores de refracción las inserciones de textos halógenos, ya publicados o inéditos, a veces netamente dirigidos a favorecer una síntesis de acontecimientos y otras veces a reponer en primer plano la escena de la escritura. Algunos de esos textos agregados producen un efecto de lectura de fuerte convocación hacia el presente y recuerdan que "se escribe sobre lo que está sucediendo en el momento de escribir" (II, 150).

23 En cambio, las arquitecturas disímiles de los tres volúmenes están elaboradas sobre el principio de desestructuración ostensible de las convenciones de un diario canónico. En todos, las series de notas ordenadas por años se encuentran enmarcadas o interrumpidas por otros textos insertos, siendo quizás la más significativa de esas tres arquitecturas la del primero, porque obedece a un programa que expone no sólo los tramos, sino las pruebas del aprendizaje, todas diferentes entre sí.

24 Cada serie de notas correspondientes a un año está seguida aquí por un texto que se relaciona de un modo u otro con la etapa evocada. El procedimiento evoca la metáfora del "laboratorio" de la escritura, frecuentemente aplicada por el autor a sus diarios personales: se incluyen cuentos publicados, inéditos y semi-inéditos ("Primer amor", "En el bar El rayo", "El nadador", "La moneda griega") ${ }^{14}$, un cuento de ambiguos límites genéricos ("Una visita"), otro en forma de diario ("Diario de un cuento (1961)"), un ensayo ("Los diarios de Pavese"), un autorretrato en forma de cuento ("Hotel Almagro"), un prólogo ("Quién dice yo?"), una nouvelle ("Canto rodado"), y dos relatos- marco ("En el umbral" y "En el estudio"). Si éstos dos últimos confirman al diario como un testimonio del presente de la escritura, situando con datos autobiográficos verdaderos e inventados la personalidad del locutor (Renzi) en contexto, la organización del conjunto recuerda el principio combinatorio de los textos más auto-ficcionales de Piglia. Por ejemplo, la nouvelle doble "Prisión perpetua", donde una ficción autobiográfica y teórica ("En otro país") era seguida por la prueba por la escritura (el cuento "El fluir de la vida"); o bien "Nombre falso", donde la investigación sobre el texto perdido ("Homenaje a Roberto Arlt") era seguida por una muestra de escritura apócrifa (“Apéndice: Luba"). El plan del volumen I recuerda por fin el montaje del libro Prisión perpetua en la edición argentina de 1988, donde el relato auto-ficcional del mismo título va seguido por los seis cuentos que dan prueba de la obra del escritor, mientras a éstos sucede, como un espejo invertido, la doble nouvelle "Nombre falso", que prueba en cambio la fragilidad de la autoría y la capacidad de la escritura para circular y volverse propiedad de otros ${ }^{15}$.

Se puede decir entonces que el plan del tomo I está destinado a consolidar la lógica de la dupla vida (de escritor) /obra (de escritor). El procedimiento, sin ser nuevo, acompaña aquí la biografía (real y ficticia) del que enuncia e insinúa un valor pedagógico de transmisión del aprendizaje. El libro definitivo (I) se acerca tanto al retrato del artista cachorro como al museo (archivo) personal de un escritor.

El segundo volumen de los Diarios plantea un nuevo desafío: la invención de las "series" temáticas como posible respuesta al problema de cómo ordenar los acontecimientos de una vida. Las notas por series aparecen y desaparecen en medio de las que están regularmente regidas por la cronología anual, siguiendo una estrategia que muestra una vez más la imposible homogeneización de la escritura y los hechos. Al tiempo que su 
marco introductorio comenta irónicamente la falsedad de la escritura autobiográfica y los impasses de la selección serial ("En el bar", II, 8), este volumen omite el recurso a los textos literarios insertos, pero ofrece materiales esenciales sobre los proyectos del escritor, su participación en debates y publicaciones en una época de gran fertilidad intelectual (1968-1975), la génesis de sus novelas (en particular Respiración artificial y Plata quemada), y la importancia creciente de su trabajo crítico.

Las modalidades previas se combinan dentro de un armazón más aluvional en el último tomo, donde la transformación de materiales exhibe resultados aún diferentes. Si los diarios cronológicamente ordenados (sección I, desde 1976 a 1982), están enmarcados por capítulos ("Sesenta segundos en la realidad" y "Los finales"), que atraen la enunciación hacia el presente como en los anteriores volúmenes, a esta parte le siguen dos grandes experimentos narrativos sobre el tiempo. El primero de esos experimentos adopta la forma de la "vida serial" (sección II), es decir, presenta a lo largo de diecinueve subsecciones el relato de veinticuatro horas en la vida de un hombre, sólo que esos momentos corresponden ficticiamente a un mismo día, pero ocurren en diferentes años. Se trata de secuencias narrativas organizadas en torno a dominantes temáticas diferentes (la muerte, el olvido, la ciudad, la clandestinidad, la política, la música, etc.), como líneas cromáticas o tonos musicales que caracterizarían las constantes o los momentos clave de una existencia, capturados entre el 16 de junio de 1983 (168) y el mismo día del año 2000 (243). De este modo, la síntesis caleidoscópica cubre el bache que surge después de las anotaciones de 1982 al cerrarse la primera parte, y la figura de la alteración temporal confirma que la repetición y la variación son los principios que rigen la dinámica de la existencia humana, tanto como rigen el esquema subyacente del diario.

En la última parte del volumen, el segundo experimento con el tiempo toma a su vez la forma de once notas ordenadas por temas y días de la semana ("Días sin fecha"), que cubren años más o menos recientes, a veces explícitos o sugeridos, a veces no. Tales "días" proponen fragmentos que se organizan en torno a un motivo (un título); el tiempo cede aquí el lugar al espacio, al pensamiento, a las topografías, las marcas, las atmósferas de algunos momentos de vida. El pasado remoto se inclina ante un pasado cercano y, hacia el final, cede ante el presente. Así, el libro termina ficcionalizando nuevamente la escena actual de la escritura, en un eco ostensible de los capítulos que a lo largo de los tres volúmenes han operado como textos de encuadre.

Vistos desde esta perspectiva somera, los Diarios practican a la vez el descrédito de la rutina del diario personal y la preservación de un texto que corresponde a esa categoría; un texto preexistente, escrito con cierta regularidad a lo largo de años. Se lo preserva sin embargo siempre que ese texto cambie y se vuelva una imbatible máquina de narrar, un dispositivo creador múltiple. La desaprobación concierne entonces fundamentalmente la índole mimética del discurso y lo inesencial del suceso cotidiano, la estrechez de la forma del diario íntimo; el descrédito se ejerce sobre la retórica sentimental, acompañante indeseable de las confesiones personales; la desconfianza surge de la fijeza de una notación que sólo se refiera al pasado. El impulso de preservación, en cambio, se aplica a las huellas de la vida que permiten imaginar otros destinos posibles o volver a pensar el pasado a la luz del presente.

Llevando sus cuadernos hacia la literatura, insertando en ellos otros diarios inexistentes o escritos casi contemporáneamente a la publicación, usando la cita intratextual y la variación de tonos, Piglia evita la trivialidad, la saciedad, la saturación del género, y hace de los Diarios una enciclopedia de sus temas y preocupaciones. Como en un sueño, en el 
resultado final está toda la memoria diurna de una vida de escritor, pero con la sintaxis y el timbre de voz cambiados.

\section{Autores y enunciadores}

31 La línea narrativa que domina el proyecto del diario en tanto obra orgánica podría en efecto identificarse como «la novela del escritor». Los Diarios relatan sus años de formación, sus modos de vida, sus lecturas, amores y amistades, sus dificultades, comentan las estéticas e ideas a las que adhiere, los textos que escribe o quisiera escribir, hasta el momento en que su reconocimiento es indiscutible, una vez publicada Respiración artificial (1980), momento que por otra parte coincide mayormente con un final anhelado en el tiempo político, la agonía (1982-1983) del régimen militar. Aunque las notas del diario discuten a menudo la supuesta unidad del yo y afirman la dispersión de la conciencia, no dejan sin embargo de rastrear los «filones de la vida íntima» (Segre 2000) $\mathrm{y}$, como los diarios de otros autores contemporáneos, ofrecen una mina de observaciones sobre las conductas, los afectos, las obsesiones del que escribe. El diario introspectivo se enlaza así estrechamente con el diario de trabajo, que entrega un registro minucioso de los avances y retrocesos de cada proyecto literario. Pero ese diario que aparece bajo la autoría de Piglia está atribuido a Emilio Renzi, que es igualmente el sujeto, en tanto locutor/narrador y personaje protagonista, de cantidad de textos a lo largo de los tres volúmenes, y en especial, de todos los fragmentos y subcapítulos que acercan el relato al presente de la composición.

Indudablemente, el hecho de recurrir a la figura de papel más notoria de las que Piglia ha creado para representar su propia voz aparta la posible verdad de los hechos de su verosimilitud narrativa ${ }^{16}$, impregnando toda la «novela de la vida» con el color de lo inverificable de la ficción. Sin embargo, el gesto tiene aquí una dimensión diferente de la habitual puesta en ficción del personaje de Renzi -el otro (como) yo (mismo)-, porque opera como disparador de un doble efecto. Por un lado, consolida la lectura de los diarios de Piglia en tanto forma de discurso biográfico inseparable de la literatura. Y simultáneamente, opera un juego de distanciamiento: distancia la condición del escritor de la situación de escritura, lo distancia de las formas de la realidad que lo alcanzan o lo han alcanzado, y enuncia esa distancia como un dispositivo eminentemente literario, un desplazamiento hacia la voz de otro que habla en su propio nombre (el de Renzi), pero retraduce la experiencia (el punto de vista) de Piglia. El juego de alternancia o de enmascaramiento Piglia/Renzi sugiere además que se trabaja -en esta etapa última como en las anteriores- con una idea de la creación literaria que privilegia la historia de los combates con la escritura, el personaje del escritor que no es aún una figura pública, la biografía intelectual y literaria del que solamente más tarde será "Piglia". La vida del que escribe, por su parte, pertenecería a una dimensión diferente, a la vez real e imaginaria, secreta y demasiado evidente, esencialmente ficcionalizable y abierta al azar, a la improvisación y a la interpretación. La vida sería una metamorfosis legible sólo en la literatura. O, mejor aún: lo tangible, lo aceptable, lo inteligible de la vida es siempre el resultado de una mutación donde el principio activo es la escritura; más que tratar de saber qué es lo que en la obra (o en un diario personal) procede de la vida, se trataría entonces de averiguar cómo la escritura o la lectura definen la propia experiencia. La mediación entre los términos del conflicto es esa voz de(l) otro con la que se escribe la literatura: "Como se ve, este cuaderno tiende a marcar sobre todo mi biografía 
intelectual, como si la vida se fuera dibujando sin otro movimiento que el de la literatura. [...] [L] a obra construye el modo de vivir." (II, 39-40). El diario se "escribe para poder leer desplazando el sentido", dice Piglia de Kafka (2005: 236). El diario es la biografía de otro: "siempre es otro -no soy yo- el que escribe". (II, 65)

La historia personal que detallan los Diarios sigue en nombre de ese doble rostro las huellas de Piglia en La Plata y en Buenos Aires durante más de dos décadas y actualiza, con datos a menudo verificables, toda una arqueología de la vida intelectual de los sesenta y los setenta, una vida en el siglo y en la ciudad, con sus artistas en busca de espacio social, sus revistas, librerías, bares, costumbres, luchas políticas, ideas y rivalidades. Leer sin mediaciones a Piglia en Renzi sería sin embargo inoperante: como Ratliff antes, Renzi habita la línea compleja que circula entre la autobiografía imaginaria, la biografía ficticia y la memoria autobiográfica. A través de su figura tomada en préstamo como una máscara, escrutando sus reflejos narcisistas, Piglia se interroga sobre sí mismo con constante distancia irónica, la convierte en un puente para apartarse de sus propias opiniones y valoraciones o para confirmarlas poniéndolas en boca de otro.

El personaje de ficción Emilio Renzi pertenece efectivamente a los "años de formación" que el diario registra. Aparece ya en cuentos de los primeros libros ("La invasión", "La loca y el relato del crimen", "Homenaje a Roberto Arlt", "El fin del viaje"), o bien en otros publicados más tarde, pero cuyos borradores datan del mismo período ("El pez en el hielo"), y se lo encuentra en todas las novelas, con importancia variable de su protagonismo ${ }^{17}$. Cuando Renzi envejece o declina, se le adjunta Junior ${ }^{18}$, como amigo fraternal más joven ( $\mathrm{La}$ ciudad ausente, Blanco nocturno); cuando llega el momento de enunciar con nostalgia la caducidad de los ideales de la generación del autor, la narración adopta la primera persona puesta en boca de Renzi (El camino de Ida). Como otros sujetos de escritura ficticia, autores de diarios (Steven Stevensen), de cartas (Maggi) o de confesiones (Ossorio), en los cuales se refugia una identidad esquiva, Renzi parece estar muchas veces a punto de desaparecer, pero su voz perdura en el corpus, portadora de una sintaxis oral que es indispensable a la unidad polifónica del relato. Cuando llega a las páginas de los Diarios, el personaje es ya el autor de una obra visible/invisible; el lector conoce el carácter de algunos de sus escritos personales, sabe de sus búsquedas de escritor, de sus opiniones de erudito y de amateur, de sus desequilibrios y pasiones intelectuales.

Por otra parte, la atribución de la escritura al nombre de Renzi, con el que Piglia firma también algunas traducciones y trabajos críticos ${ }^{19}$, usufructúa un apellido que le llega por vía de su familia materna ${ }^{20}$. De modo que ese nombre ficticio, portador de un proceso de distanciación, implica además una selección dentro de la genealogía y remite a la construcción de la novela familiar del escritor. En los Diarios, la madre detenta una forma de anárquica capacidad de hacer uso del lenguaje; es la voz de la invención, la dadora de las historias de familia (passim), celebradas como inagotable cantera de ficciones. En la vía matrilineal se asienta entonces irónicamente la pertenencia a una familia diferente, la de los que se crean a sí mismos en contra o al margen de la legitimidad del padre, la familia literaria, que tiene sus leyes propias: "silencio, exilio y astucia", según el muy citado consejo de Joyce. Al contrario de la creación de un seudónimo, la estrategia de adopción de ese nombre para identificar la escritura de la vida personal esboza como el dibujo de un autógrafo y convoca más o menos abiertamente una historia familiar transfigurada. Por eso, el enmascaramiento en Renzi puede pensarse, en lo que se refiere a los Diarios, más allá de la continuidad del personaje de ficción, y más que como refugio en una 
sombra o un doble, como presencia de un verdadero interlocutor en el que se pone en juego la relación entre el yo y el otro propia de todo acto de escritura personal, una figura oximorónica de la semejanza subjetiva que trasciende la impersonalidad del lenguaje.

Gracias a ese interlocutor, el diario publicado responde al proyecto de transformar las huellas de lo vivido en obra y de exhibir el nombre de pluma como un mito de escritor, sin dejar de contrastarlo con las otras figuras que componen la familia imaginaria (y real) de la tradición argentina. Forja de un lugar futuro, que debería en adelante ser irrebatible, el diario coloca al escritor del doble nombre entre sus pares, en una familia de elección que está signada por la afinidad (amistades y enemistades) y no por el destino. Se trata de una empresa donde los lindes temporales son sobre todo variables de ajuste. Piglia construye su foto de grupo como construye sus conceptos de generación o de vanguardia, críticamente, libremente, polémicamente. El "destiempo", el "contratiempo", las "interrupciones" de Renzi son parámetros que le permiten mirarse y señalarse en situación, silueta en contraste con los lugares comunes del momento o de la tradición, fiel a sus ideas y a sus afinidades electivas, en busca de nuevos desafíos literarios y en combate franco contra la contingencia y el renunciamiento a las convicciones (la "conversión" de tantos otros intelectuales).

En este sentido, el diario publicado podría considerarse como un hijo intrépido de ese imaginario de la eternidad que es quizás inevitable en toda escritura personal. En su "microscopía del tiempo y del recuerdo" (II, 164), donde se procesa un sujeto que intenta controlar el pasado y cambiar el presente, el nudo parece anudarse en la fantasía de ser para siempre semi-inédito y semi-póstumo (valga lo inexacto de los términos), arropado en la novela futura e inconclusa de un nombre doble.

\section{El diario y las voces}

El diario de Piglia estaría contenido en 327 cuadernos de tapa negra de hule, del tipo de los que usaban los escolares en la Argentina, marcas Triunfo o Congreso ${ }^{21}$. El punto ha sido evocado muchas veces por el autor en sus entrevistas y la cifra da título al film de Di Tella ya citado (2015). Hay tomas de la película en donde se enfocan algunos cuadernos y en una escena se ve a Piglia quemando un ejemplar; por su lado, en diálogo con periodistas, Di Tella afirma que se quemaron tres y que Piglia pensaba quemarlos todos después de transcribirlos (Garzón 2015) ${ }^{22}$. La construcción literaria de los Diarios cuenta así con una imagen externa que se ha ido preparando poco a poco desde los primeros anuncios de la existencia de un diario personal del escritor, imagen que cobra finalmente el carácter de una narración fílmica. La cifra que la acompaña no es anodina y suena como un desafío referido al cúmulo de anotaciones que equivaldrían a la escritura de una vida.

Sin embargo, la cantidad ingente de cuadernos citada no coincide con la de los archivos de Princeton, en los que se puede contabilizar menos de una centena, que corresponden global y aproximadamente a los años que abarcan los Diarios publicados. Puesto que el registro de anotaciones regulares según el calendario se detiene en los años ochenta, tanto en los volúmenes definitivos (1982) como en los cuadernos de los archivos (1988), se puede imaginar que los ejemplares de los años siguientes han sido destruidos para hacer coincidir archivos y libro, publicación y fuentes, pero también se puede conjeturar que se han perdido, o incluso que no han existido nunca ${ }^{23}$. 
40 Entretanto, la pregunta sobre el dato cuantificado persiste: ¿habrían quedado sólo unos ochenta cuadernos sobre más de trescientos, es decir, una cuarta parte de la escritura inicial? La posibilidad de una destrucción amplia queda abierta, pero una coincidencia llama de todos modos la atención. Invirtiendo cifras, se obtiene una cantidad que remite a la biografía de un escritor venerado: 237 sería el número de esquirlas de obús que hirieron al joven Hemingway durante los meses finales de la guerra de 1914-1918. Piglia menciona ese dato probablemente inventado, sin extenderse a comentarlo, en su breve ensayo sobre Hemingway incluido en "Escritores norteamericanos" (2015: 134) ${ }^{24}$. En ambos escritores, la cifra parece entonces una hipérbole que contribuye a una leyenda personal, la del heroísmo en Hemingway, la de la escritura que dura lo que dura la vida en Piglia. Evidentemente, para éste se trata también de un homenaje secreto a uno de los autores que más ha admirado.

41 Ya en ese ensayo que data de 1967, Piglia inicia la presentación del norteamericano con el relato del episodio de guerra y de su heroísmo de soldado, y retoma luego una fórmula de Hemingway -“"“Yo morí entonces”, dijo" (134) -, que sugiere la imagen del escritor futuro como un muerto en vida, como una voz extrañamente sobreviviente. Es la misma voz del que "está muerto y lo sabe", del que habría dictado su testamento al recoger en volumen sus mejores cuentos (en 1938), sabiendo que el resto de la obra no podía comparárseles. Por cierto, varios de los cuentos más preciados de Hemingway son historias trágicas que ocurren a personajes amenazados de muerte, como el escritor de "Las nieves del Kilimandjaro", o el protagonista de "La breve vida feliz de Francis Macomber", o los soldados de "Historia natural de los difuntos". Pero la idea de una enunciación procedente de un hombre en las orillas de la muerte encuentra en Piglia un eco que se puede rastrear dentro de un espectro amplio de casos y que va más allá de la reconducción más o menos visible de un tópico literario. La frase de Hemingway vuelve incluso en los Diarios, evidentemente sin mención de fuente, como un deseo del que suscribe: "Terminar un texto (este diario, cualquier otro) con la frase: yo he muerto" (III, 31).

42 A su vez, como una invitada indeseable y paradójica surgida de la realidad, la condición de enfermo grave de Piglia en el momento de la redacción definitiva de los Diarios, eminentemente susceptible de un tratamiento ficcional, viene a hacer eco a esa figura imaginaria de la voz situada en el limes de la vida. En los Diarios, la preocupación por el tema está ficcionalizada en las páginas en que se alude de manera a la vez sobria y sobrecogedora a la destrucción progresiva del cuerpo del escritor por efecto de la enfermedad (sobre todo en III, 293-294), así como, más irónicamente, en la genealogía que se inventa a Renzi a través de la aventura italiana de su abuelo Emilio. Esta historia de un hombre destinado durante la guerra en Italia al servicio encargado de la correspondencia y haberes de los soldados desaparecidos (I, 24-25; 103-104; 339; 346-347) se reitera en el primer volumen como una escansión. Las cartas del abuelo, anunciadoras de malas nuevas, y las de los soldados han sido escritas por hombres que van a morir; algunas están "a medio escribir, todavía no enviadas o interrumpidas por la muerte" (103). Se trata por cierto de un motivo de arrastre literario que viene de Melville (Bartleby, el escriba), pero que cobra una inflexión específica en la versión de Piglia, donde también es pertinente para sugerir la idea de que el heroísmo es una experiencia familiar imposible de alcanzar -un poco en la línea de la meditación borgiana sobre el Coronel Francisco Borges, o tal como se da en circunstancias biográfico-literarias de Faulkner, otro escritor admirado-. 

también presente en cantidad de anotaciones crítico-narrativas referidas al tema de los artistas suicidas (I, II) y en particular a Pavese y al enigma de la escritura prepóstuma. Estos apuntes son esenciales, porque cuestionan directamente la relación entre vida, escritura, muerte y posteridad. Es claro que la huella de Pavese en los años de formación de Piglia está relacionada directamente con la estatura intelectual del italiano, con su dedicación sin fallas a la literatura, con la calidad de sus relatos, aspectos todos que los Diarios documentan ampliamente en la década del sesenta (I y II, passim ${ }^{25}$. Pero la fascinación por el diario de Pavese, primero ligada a los problemas existenciales y amorosos de éste, tiene rápidamente que ver con su intención suicida explícita en diferentes pasajes, que hace de él una suerte de encarnación del escritor que opera desde la posición del ausente, de aquel que todavía habla, pero ya (casi) no es. Por fin, Pavese cierra en efecto su diario y lo prepara para el lector futuro desde la pieza anónima de una pensión turinesa muy pocos días antes de darse muerte, una situación que es fuente de relectura obsesiva por parte de Piglia (por ejemplo, en II, 60), quien evoca el tema aún en años recientes (en entrevista con Larre Borges y Bajter, 2011). En el ensayo que data de 1963 ("Los diarios de Pavese"), inserto en el primer volumen, dice:

Relato vacío, relato donde sólo se registra el pensamiento (de la muerte), al mismo tiempo Pavese escribe el diario para postergar el suicidio. En este sentido el trabajo con el doble [tu] es, como siempre, un modo de conjurar la muerte. Texto límite, el deseo que lo recorre es el de estar muerto y a la vez poder escribir sobre esa muerte. Esta es la contradicción que resuelve imaginariamente el mito del doble que se fascina con la idea del suicidio. La última frase del texto, implacable, hace ver que la escritura era su única (última) defensa [...].

Libro donde se trenzan la muerte y la escritura, el diario de Pavese es uno de esos raros documentos [...] para los que la literatura no termina de encontrar un lugar. A trece años de su fin, la lectura de ese libro casi perfecto asegura el único recuerdo de Pavese que interesa. Él es ese libro. (I, 146) (Subrayado mío)

Si se dejan de lado los Diarios para explorar la problemática de la enunciación como registro de una voz en la frontera entre dos mundos, las pruebas no faltan en el corpus ficcional. El imaginario del locutor ausente o muerto reaparece en la escritura de muchos cuentos y cristaliza, en tiempos de redacción propicios a la evocación alegórica de la muerte (1976-1980), en la primera novela, Respiración artificial, donde se lo puede observar ampliamente declinado, con variaciones que van desde las cartas de los desaparecidos hasta los papeles póstumos de Ossorio ${ }^{26}$. En los cuentos, los casos más notables se encuentran en "La mujer grabada" (Formas breves, 1999: 41-46) ${ }^{27}$, propicio a una lectura meta-literaria (Orecchia Havas 2010: 357-364), y sobre todo, en "Un pez en el hielo" ( $L a$ invasión, 2006: 175-194), una nouvelle cuya muy larga gestación se puede seguir en los dos primeros tomos de los diarios ${ }^{28}$, y que convoca a Renzi en una intriga tejida precisamente en torno al personaje de Pavese.

En ese texto la perspectiva se precisa, dramatizando las condiciones de la enunciación literaria. Piglia dice, traduciendo literalmente un fragmento del diario de Pavese: ““”En el fondo tú escribes para estar como muerto, para hablar desde afuera del tiempo, para convertirte para todos en un recuerdo"'. Y enseguida, después de citarlo en el original (" In fondo, tu scrivi per essere come morto") ${ }^{29}$, agrega: "Estar afuera de la vida. Kafka pensaba algo parecido" (183).

Viene entonces a continuación un fragmento probatorio del diario de Kafka:

Aquel que no haya logrado alguna forma de acuerdo con la vida, necesitará de una de sus manos para alejar de sí en lo posible la desesperación que le causa su destino 
[...] pero con la otra mano podrá anotar lo que vea bajo aquellas ruinas, pues verá otras cosas, más cosas que los demás, ya que estará muerto en vida y será el sobreviviente real. (184) años de composición final de los Diarios; es temprana y se construye en relación con lecturas ${ }^{32}$ y con fantasmas personales. Pero cuando el propio tiempo de vida de Piglia está próximo a acabar, la imagen del escritor como un muerto en vida no elude la desaparición inminente del cuerpo, que el sujeto ambivalente del diario incorpora como un acontecimiento posible, quizás próximo, en la vida de Renzi. La imagen del diario, como en el film de 2015, se convierte así paralelamente en un recuerdo del porvenir, una vasta inscripción que cobra su estado definitivo sólo cuando la muerte se aproxima y el cuerpo mismo se consume. El presente de enunciación de las páginas finales corresponde a esa convergencia imaginaria que resalta ahora con los tonos de una secuencia dramática (III, 293-294), en la que alguien habla en primera persona desde un tiempo detenido.

El cruce de lo imaginario, lo fantasmático y la realidad biográfica sugiere que la copia y reescritura del diario, mil veces prevista, iniciada, comentada, abandonada, ha encontrado su momento oportuno (su kairós), su pertinencia, su motivación ineludible, ante el anuncio de un fin de vida cercano. Recuerda que los diarios se seleccionan y corrigen por última vez de cara a una publicación inminente, en un trabajo inaudito completado en una situación extrema que podría verse como testamentaria. En cambio, la mitificación de la cantidad de originales, que exalta secretamente el cuerpo del escritor expuesto a innumerables heridas simbólicas, y el recurso a la máscara y la voz de Renzi ${ }^{33}$ confiscan y desvían esa dimensión postrera. Entregan el texto al curso interminable de la palabra metafórica y ficcional, acuden a la literatura en tanto forma estilizada de juego sagaz con la muerte, juego de pistas incansable, destinado a repetirse en cada nueva lectura. 


\section{Viaje a la creación}

51 Según este esbozo de lectura, los Diarios de Piglia/Renzi remiten a una figura autoral cuyo nombre se declina en una versión literaria destinada a ser póstuma como un autógrafo trazado en la proximidad de la muerte, pero a la vez se interrogan sobre el origen secreto de la voz que habita el cuerpo del artista y que resuena en la escritura. Son un poco como el viaje de Orfeo de Piglia, en el cual se sintetiza el doble movimiento de la creación literaria, inquisidora de su propio origen, pero empujada hacia el futuro de las formas. Resignifican el movimiento contradictorio del escritor colocado frente al impulso de la obra, vuelto hacia una surgente a la que no puede ni abandonar ni seguir contemplando indefinidamente, pero a la que desea conjurar como una versión final -aunque difícilmente definitiva- de toda su literatura.

La mirada de Orfeo es el don último de Orfeo a la obra, don por el cual él la rechaza, la sacrifica, lanzándose hacia el origen con el movimiento desmesurado del deseo, y [don] por el cual se lanza, sin tener conciencia, de nuevo hacia la obra. (Blanchot 1973: 232. Mi traducción) ${ }^{34}$

En este sentido se pueden interpretar igualmente las notas de los Diarios que dan cuenta de la dificultad de pensar (II, 65) y de la aporía que aprisiona el pensamiento cuando se intenta comprender el sentido de la creación:

\footnotetext{
¿Qué busco? Siempre lo mismo, conocer por qué [Pavese] escribe, qué o quién lo llevó a eso -como a mí-. (II, 68).

Hay algo raro en la decisión de elegir lo imaginario como razón de la vida misma. Una falla, una fisura que nadie ha visto pero cuyas consecuencias se sienten en el lenguaje, en una disposición turbia y problemática de las palabras. (II, 69)

Desde hace casi quince años busco una letra (sic) que apenas entiendo [...], en cuadernos con tapa de hule negro donde hablo de mí, sin saber muy bien cuál es el sentido que trato de captar. Para entender mejor esto que digo conviene que trate de explicar qué fue (qué es) para mí eso que convenimos en llamar literatura. (II, 313)
}

Como la de Orfeo, la travesía del diario reúne el principio y el final, obliga a revisitar el origen, informa sobre la necesidad de sobrevivir al peso de los días y da cuenta de la tentación del silencio y de la transgresora proximidad de la muerte, ese momento en que se "transforma el grito en obra" (Todorov 2006: 148). Sus páginas, que incluyen una puesta en literatura exhaustiva del acto de escribir, hacen ingresar en ella todas las contingencias, sin olvidar la enfermedad. La imagen fílmica de la quema de los cuadernos negros (uno o varios), de vocación simbólica y prosapia literaria, señala quizás aquí el fin del viaje, el empuje de la realidad que penetra de golpe en el juego del imaginario como una combustión destruye súbitamente el celuloide de una vieja película.

Por supuesto, los diarios contienen también su propio relato mítico. Son las páginas en las que vuelve el tema de la "grieta" existencial que la escritura disimularía o colmaría (I, 143) y del diario como "un jeroglífico lleno de silencio y de oscuridad" (145); o bien aquéllas que mencionan lo interdicto, "lo que no se puede ni decir ni hacer" (I, 184), que debería ser el único objeto de las anotaciones, y aluden al secreto ${ }^{35}$ del diario, ambos como materia ausente, denegada. El cuerpo enfermo desaparece tras la imagen de ese otro cuerpo que está hecho de literatura: "Esa expresión, "mi cuerpo me es ajeno" abundaba en sus diarios, desde su lejana juventud había empezado a vivir en el cuerpo de 
otro. "Por eso me hice escritor", dijo, "para mantener a raya y observar detenidamente a ese extraño que se había adueñado de mi cuerpo.”” (III, 343)

Este relato del diario, como todo relato mítico, es oximorónico; especula sobre un final interminable ("Morir es difícil", III, 293), pero al mismo tiempo dice que la muerte "sirve para algo" (Barthes) ${ }^{36}$ en las palabras con las que se cierra el último volumen: "El genio es la invalidez" (III, 294). Colocada a modo de conclusión, esta fórmula dramática de apariencia contradictoria define la situación inmóvil y parca del sujeto que enuncia en tanto dato existencial, y no sólo como accidente, y sugiere que el cuerpo es un combustible, el alimento de la excelencia. Si la tradicional imagen idealizada del intelectual lo suele presentar como una suerte de monje laico encerrado en su célula, la frase de cierre recuerda la condición sedentaria propia del que escribe y el silencio que es también materia esencial del lenguaje. Atenuando su tono patético, se la puede entonces leer como ambivalente, y referida a la situación de clausura que el diario menciona a menudo, al difícil ejercicio de inmovilidad ligado a un destino de escritura ${ }^{37}$. Sólo que esta vez esa estación inmóvil ha facilitado la transcripción del diario, "[l]a última obra gravitacional y extensa" (III, 234), la obra genial ${ }^{38}$, en la que se refrenda el carácter invencible de la literatura.

La vida escrita pesa ${ }^{39}$ porque, según Piglia, el pasado es de alguna manera opaco, ilegible, y su sentido sólo se encuentra después de la muerte (passim). Querer cambiarlo en la escritura es por eso "una superstición", "un efecto de la literatura" y "un gran tema novelístico" (I, 242). Pero su registro en el diario permite la relectura, que es "un modo de volver a vivir el presente" (I, 318), el único tiempo desde el que el sujeto accede al otro yo mismo en cuyo nombre habla: "El narrador habla de sí mismo en primera persona como si se tratara de otro, porque habitualmente construye su vida desde el final de la sucesión que está narrando, es decir, desde el presente de la escritura" (II, 28).

En consecuencia, el elogio del (último) lector se inscribe en los Diarios con una nueva inflexión que lo liga al mundo de los afectos, reencontrados no en la eternidad del recuerdo, sino vivos en el presente, recuperados en la profundidad acuática de un presente que se impone en la experiencia de la lectura. Leer (haber leído) significa volverse capaz de recordar la emoción ligada a los primeros libros: "[La] cualidad epifánica [de la primera lectura] no depende del contenido del libro sino de la emoción que ha quedado fijada en el recuerdo" (I, 19). Releer el diario y reordenarlo, reescribirlo, es impregnarse aquí y ahora de la emoción por la presencia de las cosas ausentes ${ }^{40}$, entrever la intensidad de los lazos afectivos.

También en la bella leyenda de Orfeo la evocación de la frontera imprecisa de la vida se entreteje con la exaltación del afecto. El viaje, antinómico, va a la vez hacia la noche y hacia la luz, hacia la soledad y hacia el lenguaje (Graves 1967); es un trayecto que tiene su propia medida de tiempo y que es indisociable de la emoción del canto. Por eso diría, para concluir, que en la obra de Piglia el coqueteo con lo "póstumo" -la escritura del memorial, el montaje literario de la figura autoral, la articulación del texto con el testimonio personal, el don de la forma última de una literatura, la versión metaliteraria exhaustiva de una obra- es la compleja faz visible de una búsqueda que interroga subterráneamente la emoción del tiempo. La aludida intensidad del presente se inscribe como la cifra de esa búsqueda; el misterio de la creación literaria como su clave secreta (II, 313). Como el canto de Orfeo, los Diarios dicen que, si la obra del artista es de naturaleza finita, la literatura, como el tiempo y como el lenguaje, no tiene fin. 


\section{Anexo: Tres notas textuales a partir de una breve visita a los archivos de Princeton}

\section{Sobre las copias sucesivas del diario en diferentes soportes}

Los famosos cuadernos negros marca Triunfo o Congreso en los que Piglia escribía su diario (o al menos los que existen aún de la serie original) se encuentran, junto con otros papeles personales, en la división de manuscritos de la Firestone Library de la universidad de Princeton.

La consulta de los cuadernos y papeles anexos del Fondo de documentos de Ricardo Piglia (Series 1: Journals and Notebooks. Subseries 1: Journals 1954-2014) pone de relieve la constante tarea de copiado a que han sido sometidos los apuntes diarísticos desde mucho antes de que se les diera forma final en la obra impresa, situación que por otra parte resulta coherente con aquellas entradas de los Diarios en las que el escritor da cuenta de sus intenciones repetidas de copiar los cuadernos, del proyecto siempre diferido de elaborarlos como novela, etc. (Diarios, III, 140, y passim). Si ciertos cuadernos negros del Fondo parecen contener anotaciones originales, otros se presentan como copia reelaborada de ejemplares que los han precedido y que en pequeña parte se encuentran también depositados allí (éstos últimos exhiben marcas diversas: Extra, La Materia en el Arte, Mascota). En algunos casos en que se poseen entradas de igual fecha en ambos asientos se puede comprobar que, al menos en época temprana, Piglia reescribe totalmente al transcribir, o bien sintetiza en forma radical. Por ejemplo: de la nota del lunes 4 de enero de 1960 en un cuaderno Extra, que abunda en el tema de la soledad afectiva y termina con la noticia de la muerte de Camus, sólo se retiene este último dato en la entrada correspondiente del cuaderno negro (Box B 001108- Folder 8). Más tarde, en la edición de los Diarios, se la suprimirá por completo. Hay también huellas de relectura y transcripción en algunas modificaciones escritas a lápiz sobre ciertas notas, en subrayados, en cambios de tinta (de azul a negra) al pasar de un tipo de cuaderno a otro, en recuentos de trimestres copiados a lo largo de una década (1959-1969) (Box B 001108Folder 7), etc.

61 A esos materiales se agregan hojas sueltas manuscritas, así como hojas mecanografiadas correspondientes a 1960 y 1961 que contienen sin duda una copia parcial de asientos previos (Box B 001108- Folders 10 y 12). Puede ocurrir además que tales copias dactilografiadas reenvíen, en cuanto a la cronología, a diferentes tipos de cuadernos que se superponen parcialmente en el mismo período, como es el caso en el año 1960 (Box B 001108- Folders 10 a 15).

En cuanto a la práctica de transcripción final sintetizadora, un ejemplo notable se encuentra cotejando la entrada del 31 de agosto de 1970 en el cuaderno negro (Box B 001113- Folder 2) con la misma en la edición impresa (Diarios, II, 211-212). En el primero, la nota, incomparablemente más larga, cubre 11 páginas con una caligrafía de trazo laxo y rápido, mayormente sin tachados, lo que por otra parte sugiere, una vez más, que el apunte del cuaderno negro podría ser copia de una fuente anterior. La mención a Pavese, por su parte, difiere sensiblemente en ambas anotaciones (ver foto 0043). 


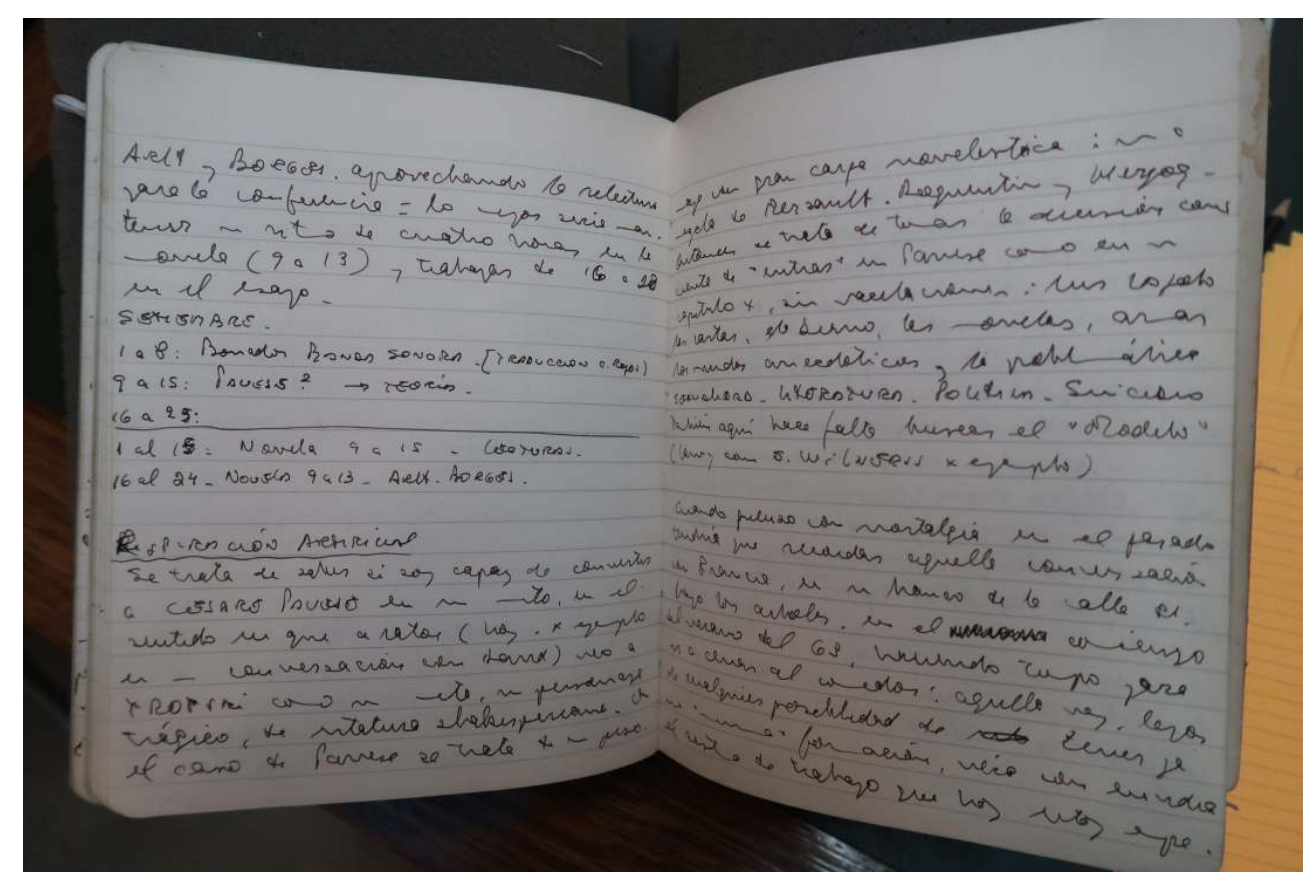

Foto 0043. Ricardo Piglia Papers (C1513); Manuscripts Division, Department of Rare Books and Special Collections, Princeton University Library

\section{Sobre discontinuidades de la serie}

63 Aun incluyendo en el cómputo los cuadernos de marca Triunfo o Éxito dedicados a anotar respectivamente los viajes a Cuba y a China, el total de cuadernos del diario no alcanza a más de unos ochenta y cinco ejemplares. La serie completa, contando los primerísimos ejemplares de la época de adolescencia que no han sido transcriptos, abarca desde 1954 hasta mayo de 1988, aunque Piglia usa a veces ciertas páginas finales de un cuaderno para consignar notas de años muy posteriores. Así, en el que cubre los meses de julio (24) a octubre (6) de 1960, se lee, con caligrafía notoriamente diferente, una nota fechada el jueves 14 de octubre de 2010 (Box B 001108- Folder 14).

Por otra parte, el caso de cuadernos que abarcan períodos discontinuos reafirma la hipótesis de probables copias sucesivas sintetizadoras. Por ejemplo, las notas correspondientes a 1987 (julio a octubre) y a 1988 (enero a mayo) se encuentran en la segunda mitad de un cuaderno que inicialmente va desde mediados de 1980 (17 de julio) a mediados de 1981 (18 de julio) (Box B 001115- Folder 2). Se trata entonces de un año entero de anotaciones a las que siguen, con otra tinta y trazo más fuerte, dos períodos situados respectivamente seis y siete años más tarde, todo contenido en un solo cuaderno. Las entradas de 1987 y 1988, que quedan de este modo un tanto enmascaradas entre páginas anteriores, cierran la serie cronológica relativamente completa (muy pocas notas de 1986, ausencia del año 1983) que había sido comenzada en 1954 (ver foto 0049). 


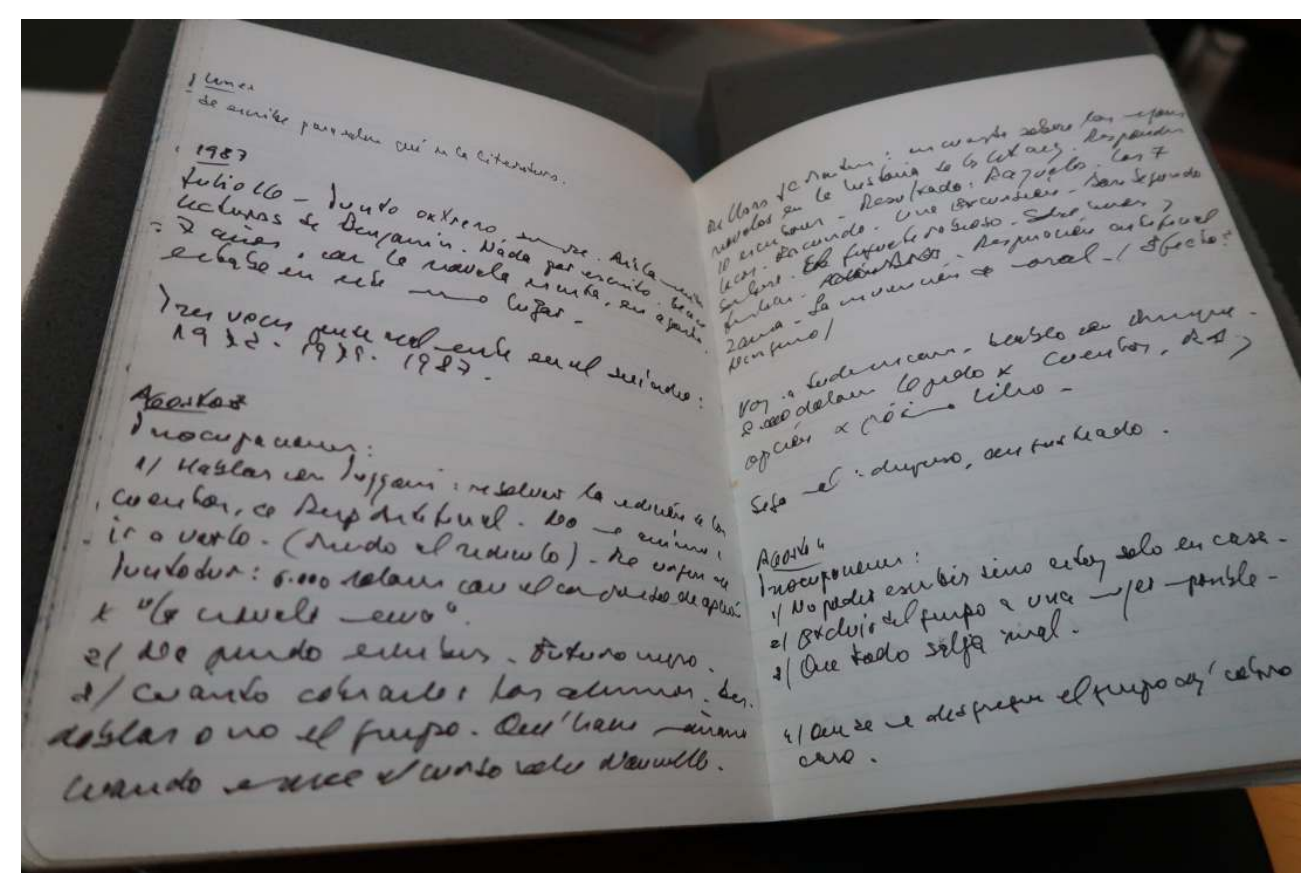

Foto 0049. Ricardo Piglia Papers (C1513); Manuscripts Division, Department of Rare Books and Special Collections, Princeton University Library

Un desafío mayor lo plantean ciertas entradas finales con fechas mucho más recientes anotadas sobre otras que han sido tachadas, visibles en el último cuaderno de la serie depositada en el Fondo (Box B 001115- Folder 5). Las notas comienzan el 3 de febrero, pero el año está tachado y modificado, con resultado poco legible (2012?). Algunas entradas dan sin embargo precisiones útiles para la datación real de estas páginas: el 30 de marzo se apunta el atentado contra Reagan, que tuvo lugar en 1981; el 10 de agosto el encuentro con José Bianco en su casa, que los Diarios mencionan en la entrada correspondiente del mismo año (III, 148); el 11 de agosto el encuentro con Daniel Balderston y la traducción en curso de Respiración artificial (III, 148). En las notas de octubre y noviembre el año aparece tachado nuevamente, pero el 13 de noviembre se señala que: "Hace un año recibía los ejemplares de Respiración artificial". Estamos pues frente a un cuaderno de 1981, de algún modo complementario del mencionado antes para ese año (Box B 001115- Folder 2). A partir de allí sin embargo la caligrafía se desordena, se usan diferentes tintas, las anotaciones llevan el año (*1999?) corregido con la fecha de 2013. La escritura es laxa, la letra grande, el trazo se descontrola; progresivamente se indican sólo los días de la semana y las últimas notas, que corresponden al 24 de diciembre de 2013 y días sucesivos, parecen escritas con suma dificultad (Folder 5) (ver foto 0054). 


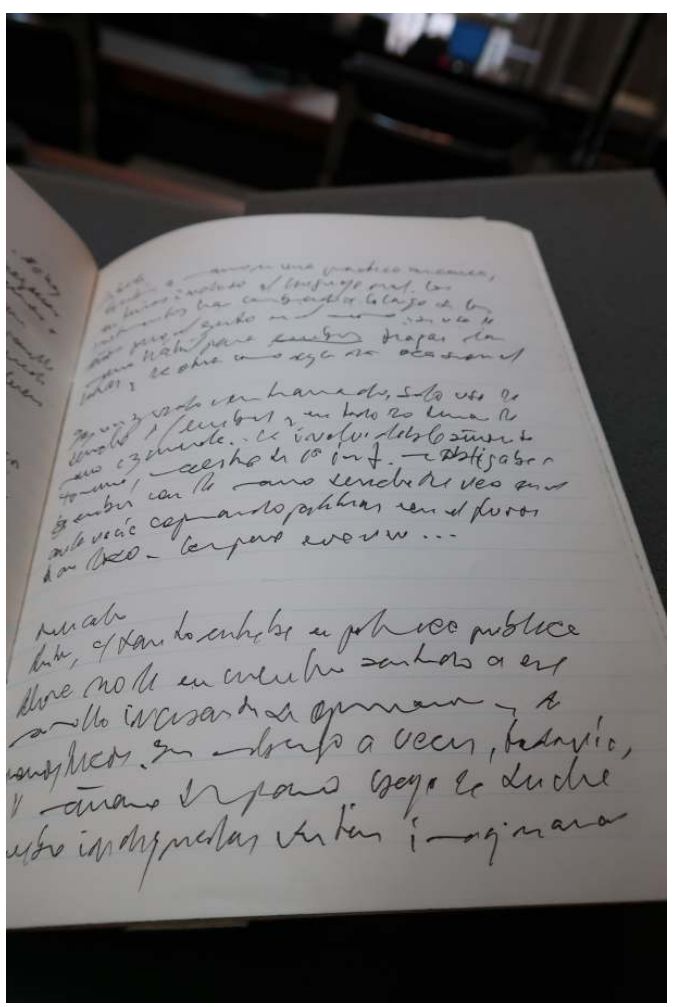

Foto 0054. Ricardo Piglia Papers (C1513); Manuscripts Division, Department of Rare Books and Special Collections, Princeton University Library

Si se omiten entonces estas pocas entradas últimas, que serían cercanas al período de composición definitiva de los Diarios y muestran una escritura atormentada y casi ilegible y una fecha laboriosamente inscrita sobre una tachadura, hay que concluir que los cuadernos del fondo, considerados como serie más o menos coherente y completa, se detienen efectivamente una vez promediada la década del ochenta. En esa serie, cada uno de los cuadernos más regularmente rellenados contiene aproximadamente un trimestre de notas, pero los hay que abarcan cuatro o cinco meses y hay también varias lagunas. Sólo un cotejo exhaustivo de todos ellos permitiría precisar cuántos y cuales faltan entre los que habrían servido a la edición de los Diarios, así como las operaciones que se han practicado sobre la textualidad original (supresiones, alteraciones, expansiones, etc.). Es claro, sin embargo, que ciertas estrategias de variación del sistema de anotación diarística habitual, que son visibles en la edición impresa, coinciden con casos de cuadernos faltantes o lacunares, y que los grandes períodos que cubren las últimas dos secciones del volumen III, desde mediados de los ochenta hasta un momento indeterminado de la década de 2010, no tienen correspondencia precisa en los archivos. Para un cotejo completo, sería probablemente útil la serie de libretas de notas sobre diferentes temas de investigación que interesaban al escritor a la que aludo en la nota anterior. Pero la cuestión de la ausencia de los diarios posteriores a 1988, tanto en la obra publicada en tres volúmenes como en los archivos, resulta independiente de las estrategias verificables de la transcripción puntual y, por supuesto, permanece abierta a la interpretación.

\section{Sobre inéditos, versiones y reescrituras: “Un pez en el hielo"}

Los archivos de Princeton contienen pruebas de la abundante actividad de escritura de Piglia, que, al menos para los años sesenta y setenta, no concierne solamente los diarios, 
(re)copiados y reescritos, ni los borradores y pretextos de libros publicados (especialmente Plata quemada y Respiración artificial), sino también da testimonio de trabajos que no han llegado a su forma final o bien cuyos materiales han sido utilizados parcial o diferentemente. Así, por ejemplo, las copias dactilografiadas de un largo relato (¿novela?) titulado "Trata de blancas”, y de otro (o bien de un capítulo del precedente) referido a "Pavese" (Series 2: Writings, 1962-2016. Subseries 1: Drafts 1962-2016 - Box B 001132- Folder 6 y también Series 3: Loose Page Notes and Drafts, 1962-1997. Subseries 4. Notes on Emilio Renzi, 1970-1971- Box B 001158- Folders 1-3). Además de sugerir datos que podrían ser útiles para la génesis de "La loca y el relato del crimen" o aun de "Nombre falso", "Trata de blancas" parece ser el original de una novela ambiciosa finalmente descartada como tal. Por otra parte, algunos sumarios o planes de texto detallados con cantidad de subtítulos, que se encuentran entre las mismas páginas y se referirían a una intriga semejante, llevan en cambio por título general "Respiración artificial" (ver foto 0064). En estos materiales, la recurrencia de nombres como el de Renzi, Larry, Almada, Morán, Dorda, Genz, Pavese, Rinaldi y otros confirmaría la circulación de personajes dentro del corpus, así como el uso del sintagma "respiración artificial" para diferentes procesos de escritura (ver Orecchia Havas 2010: 89-101). Si bien algunas de las hojas mecanografiadas están muy estropeadas y manchadas, todas son legibles y deberían proporcionar datos válidos tanto para los estudios genéticos como para clarificar la relación entre lo que Piglia se autorizó a editar y el acopio de su escritura inédita.

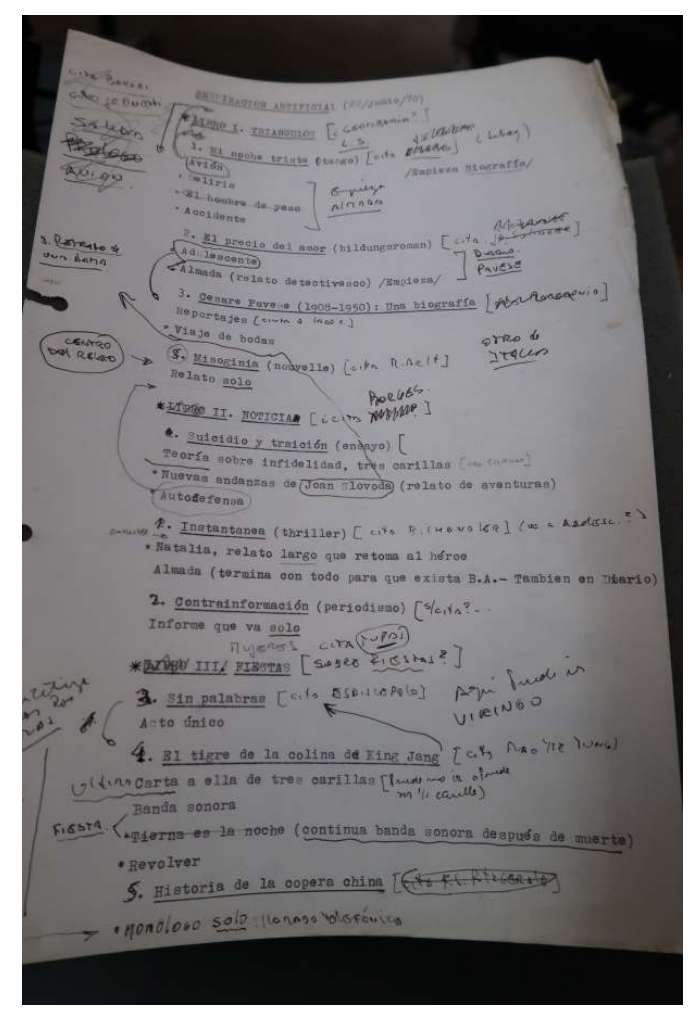

Foto 0064. Ricardo Piglia Papers (C1513); Manuscripts Division, Department of Rare Books and Special Collections, Princeton University Library

Otro ejemplo que puede evocarse brevemente aquí en relación con las compresiones y expansiones textuales es el de "El pez en el hielo". La nouvelle habría pasado por una larga gestación que ya Piglia había mencionado en el prólogo al libro que la incluye (La invasión, 2006), y que se puede rastrear igualmente en los Diarios editados. La sección "Drafts" de 
los archivos aporta a su vez dos ejemplares mecanografiados de un relato en primera persona que lleva por título "Accidente" (Box B 001132- Folder 6 -Undated) (ver foto 0056). Éste resulta notable por la imbricación entre el núcleo referido a Pavese y la historia de un accidente mortal, sin relación clara con la anterior, que muestra en cambio visible similitud con el episodio central del cuento "La caja de vidrio", publicado por primera vez en Nombre falso (1975). Las copias mecanografiadas son dos. Se trata sin duda de versiones tempranas de la ficción sobre un personaje ansioso por explorar la figura del escritor italiano, un tema también aludido en los Diarios. En la primera copia, el narrador, que tiene un proyecto de tesis sobre Pavese y no deja de pensar en él, visita la casa-museo de Santo Stefano Belbo. Su objetivo es "estudiar la escritura del destino" en la obra del italiano y escribir una biografía. Se pasea, se siente vacío, huye de las dificultades que le plantea una mujer, Laura. Conversa con un guía del museo y presencia luego un accidente, la caída de un hombre desde una torre. Aunque ve que el hombre podría pisar en falso, no avisa para detenerlo y evitar el drama. Un viejo lo mira entonces acusadoramente y él se va, pensando que dio su nombre en la conversación con el guía -y que en consecuencia se lo puede localizar-. La segunda copia es más concisa, el paisaje italiano es más sugestivo, el hombre que podría identificar al narrador negligente es otro, y el final contiene una breve escena persecutoria ausente en la primera, pero el sentido de las dos líneas temáticas centrales se mantiene.

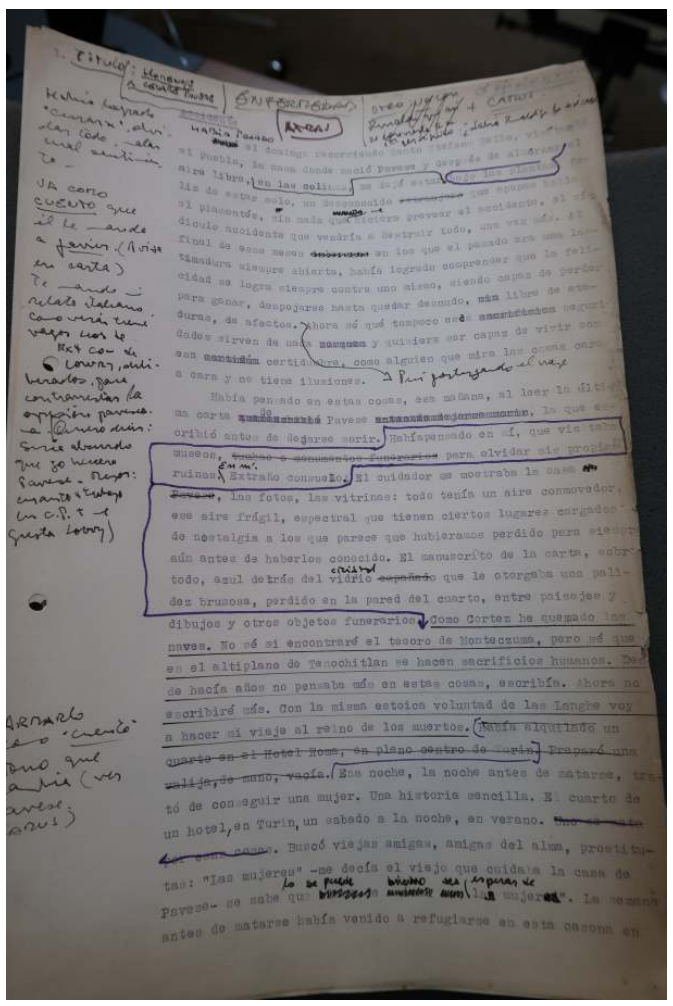

Foto 0056. Ricardo Piglia Papers (C1513); Manuscripts Division, Department of Rare Books and Special Collections, Princeton University Library 


\section{BIBLIOGRAFÍA}

A.A.V.V., El arte de narrar. Variaciones sobre Ricardo Piglia, La Biblioteca (Revista de la Biblioteca Nacional de Buenos Aires) n 15, primavera de 2015.

Barthes Roland, La préparation du roman. I et II. Cours et séminaires au Collège de France (1978-1979 et 1979-1980), Paris, Seuil/IMEC, 2003.

--- Journal de deuil, Paris, Seuil, Collection Points, 2009.

--- "Délibération", Le bruissement de la langue. Essais critiques IV, Paris, Seuil, Collection Points, 1993, pp. 423-439.

Blanchot Maurice, Le livre à venir, Paris, Gallimard, Collection Idées, 1971.

--- L'espace littéraire, Paris, Gallimard, Collection Idées, 1973.

Chejfec Sergio, "Una voz resuelta a no dejar de contar", Clarín, Revista Ñ, 28 de agosto de 2015, Web. Consultado el 11/09/ 2015.

Cillaire Sarah, "Le Chasseur Gracchus, variations (Franz Kafka, W.G. Sebald, François Bon)", Vincent Ferré y Daniel Mortier (Dir.), Littérature, Histoire et politique au XX'o siècle: hommage à JeanPierre Morel, Paris, Editions Le Manuscrit/ L'Esprit des Lettres, 2010, Web. Consultado el $15 / 05 / 2018$

Di Tella Andrés, 327 cuadernos, 2015.

Fornet Jorge, El escritor y la tradición. Ricardo Piglia y la literatura argentina, Buenos Aires, Fondo de Cultura Económica, 2007.

Frank Manfred, "Le voyage infini", La revue des Ressources, 28 février 2010, Web. Consultado el 15/05/ 2018.

Garzón Raquel, “Piglia, la película del escritor y su memoria." (Entrevista con Andrés Di Tella), Clarín, Revista Ñ, 28 de agosto de 2015, Web. Consultado el 11/09/2015.

Gianera Pablo, "Piglia-Stupía: diálogo entre la letra y la imagen", La Nación, 30 de marzo de 2012, Web. Consultado el 17/05/2017.

Goldmann Lucien, "La estructura significativa", Literatura y Sociedad, año I, n¹, octubrediciembre 1965, p. 27-33. Traducción de Emilio Renzi.

González Álvarez José Manuel, En los “bordes fluidos”. Formas híbridas y autoficción en la escritura de Ricardo Piglia, Berna, Peter Lang, 2009.

Graves Robert, Les mythes grecs, Paris, Fayard, 1967.

Hemingway Ernest, I quarantanove racconti, Milano, Mondadori, Oscar Moderni, 2016.

Kafka Franz, Journal, Paris, Grasset, 1982.

Kohan Martín, “Alter ego: Ricardo Piglia y Emilio Renzi: su diario personal”, Revista Landa, vol. 5, $n^{\circ} 2$, 2017, p. 261-272. Reproducido en La Izquierda. Diario, 10 de junio de 2018, Web.

Larre Borges Ana Inés e Ignacio Bajter, “ "En el origen de un diario siempre hay una pérdida”. Diálogo inacabado con Ricardo Piglia”, Revista de la Biblioteca Nacional (Montevideo) nº 4-5, 2011, p. 117-135. 
Matamoro Blas, “Thomas Mann en sus diarios (1937-1950)”, Cuadernos Hispanoamericanos n 513, marzo 1993, p. 7-30.

---“Cesare Pavese y la hermandad de la muerte", Cuadernos Hispanoamericanos n 605, noviembre 2000, pp. 79-86.

Montiel Figueiras Mauricio, “De la tragedia a la conspiración” (Entrevista con Ricardo Piglia), La Nación, Sección Cultura, 18 de mayo de 2003, p.1-2.

Orecchia Havas Teresa, Asedios a la obra de Ricardo Piglia, Berna, Peter Lang, colección LeiaLiminares, vol.17, 2010.

Pavese Cesare, Il mestiere di vivere. Diario 1935-1950, Torino, Einaudi Tascabile n 716, 2007.

Piglia Ricardo, Nombre falso, Buenos Aires, Siglo XXI, 1975.

--- "Notas sobre literatura en un diario", Lía Schwartz Lerner e Isaías Lerner (eds.), Homenaje a Ana María Barrenechea, Madrid, Castalia, 1984, p. 145-149.

--- "En otro país" (en "Prisión perpetua"), Prisión perpetua, Buenos Aires, Sudamericana, 1988, p 11-51.

--- "Notas sobre Macedonio en un diario" (1989), Clarín, Suplemento Cultura y Nación, 2 de noviembre de 1989, p. 1-3.

--- “Notas al margen de un ejemplar de Adán Buenosayres", Río de la Plata n 11-12, 1990, p. 409-412.

--- La ciudad ausente, Buenos Aires, Sudamericana, 1992.

--- Plata quemada, Buenos Aires, Planeta, 1997.

--- Formas breves, Buenos Aires, Temas Grupo editorial, 1999.

--- "Diario de un loco" (en "Encuentro en Saint Nazaire"), Prisión perpetua, Madrid, Ediciones Lengua de Trapo, Colección Nueva Biblioteca, n49, 2000, p. 127-155.

--- La invasión, Barcelona, Anagrama, 2006.

--- "Patos salvajes sobre un lago congelado", Revista N , 17 de enero de 2011, Web. Consultado el 20/01/2011.

---“Un detective privado", El País, Babelia, 15 de enero de 2011, Web. Consultado el 30/01/ 2011.

--- “La construcción de la señorita Erika Turner", Revista Ñ, 31 de octubre de 2014, Web. Consultado el 01/11/2014.

--- “Notas en un diario (1987)", Antología personal, Buenos Aires, Fondo de Cultura Económica, 2014, p. 253-262.

--- "Apuntes de lo que ha sido mi vida", Revista Ñ, 28 de agosto de 2015, Web. Consultado el $11 / 09 / 2015$.

---“Los libros de mi vida. Páginas de una autobiografía futura”, La Biblioteca (Buenos Aires) n 15, primavera de 2015, p. 152-166.

--- “Escritores norteamericanos", La Biblioteca n 15, primavera de 2015, p. 124-149.

--- Los diarios de Emilio Renzi [tomo I]. Años de formación, Barcelona, Anagrama, 2015.

--- Los diarios de Emilio Renzi (tomo II). Los años felices, Barcelona, Anagrama, 2016.

--- Los diarios de Emilio Renzi (tomo III). Un día en la vida, Barcelona, Anagrama, 2017. 
Piglia Ricardo y Eduardo Stupía, Fragmentos de un diario, Buenos Aires, Galería Jorge Mara- La Ruche, 2012.

Premat Julio, Héroes sin atributos, Buenos Aires, Fondo de Cultura Económica, 2008.

Pron Patricio, "El triunfo de una cierta forma de leer/ Los diarios de Emilio Renzi. Años de formación de Ricardo Piglia”, El boomeran(g), Blog literario en español, publicado el 01-12-2015, Web. Consultado el 11/01/2018.

Rodríguez Pérsico Adriana, “Los diarios de Emilio Renzi o el pudor autobiográfico”, Zama 9, 2017, p. 59-69, Web. Consultado el 15/11/2018.

Sebald W.G., Vertiges, Paris, Gallimard, Collection Folio 3842, 2010.

Segre Cesare, “Introduzione”, Cesare Pavese, Il mestiere di vivere. Diario 1935-1950, Torino, Einaudi Tascabile $n^{\circ} 716,2007$, p. V-XXX.

Todorov Tzvetan, "Préface: "Une vie dans le feu" " y "Le présent volume”, Marina Tsvetaeva, Vivre dans le feu. Confessions, Paris, Robert Laffont, 2005, p. 9-47.

--- Les aventuriers de l'absolu, Paris, Robert Laffont, 2006.

Weill Nicolas, "Elias Canetti. Pour en finir avec la mort", Le Monde des Livres, 26 janvier 2018, p. 1.

\section{Archivos consultados}

Piglia Ricardo, Series 1: Journals and Notebooks. Subseries 1: Journals 1954-2014. Ricardo Piglia Papers. Manuscripts Division. Departement of Rare Books and Special Collections, Princeton University Library.

--- Series 2: Writings, 1962-2016. Subseries 1: Drafts 1962-2016. Ricardo Piglia Papers. Manuscripts Division. Departement of Rare Books and Special Collections, Princeton University Library.

--- Series 3 : Loose Page Notes and Drafts, 1962-1997. Subseries 4. Notes on Emilio Renzi, 1970-1971. Ricardo Piglia Papers. Manuscripts Division. Departement of Rare Books and Special Collections, Princeton University Library.

\section{NOTAS}

1. Un solo ejemplo, pero de importancia: la masa ingente de los carnets y diarios de Marina Tsvetaeva, que presenta un gran interés literario e histórico, retenida primero en archivos cerrados en la Unión Soviética, ha dado lugar a una notable recensión crítica en años recientes, tanto en Rusia como en Francia (Todorov 2005).

2. Tal es el caso de Canetti, del que se publica en 2018 una parte del «océano de notas» que retienen sus archivos, un tercio de las cuales estaba ya diseminado en sus libros (Weill 2018).

3. Así Thomas Mann, que inscribe sobre el envoltorio de sus diarios la advertencia «sin ningún valor literario», y cuyos archivos, primero sellados por veinte años de secreto legal post-mortem, se abren por fin dejando paso a una cantidad sobrehumana de páginas personales que lleva años clasificar y editar. (Matamoro 1993)

4. Piglia ironiza en los Diarios sobre la moda de lo póstumo: “Ante la proliferación de libros encontrados entre los papeles -en los archivos de la computadora- de famosos autores muertos (Bolaño, Cabrera Infante, Nabokov, etc.), un grupo de escritores ha decidido ganarse la vida escribiendo novelas póstumas. Luego de varias reuniones decidieron escribir la novela póstuma de Samuel Beckett, Moran, una continuación de la trilogía. Junto con el manuscrito deben inventar la forma en que el libro ha sido 
encontrado." ("Private Eye”, III, 253). Y especula con ironía sobre el futuro de su propia literatura en la secuencia sobre el hallazgo de un manuscrito titulado "Los diarios de Renzi o Libro de Quequén", denominado también "El libro del naufragio" (III, 234).

5. "Notas sobre literatura en un diario" (1984); Fragmentos del diario del narrador en "En otro país" (1988); "Notas sobre Macedonio en un diario" (1989); "Notas al margen de un ejemplar de Adán Buenosayres" (1990); "Diario de un loco" (2000).

6. Los textos del volumen III que han sido prepublicados (2011) en ambos medios son: "Private Eye", "El perro ciego", "El consejo de Tolstoi", "El piano", “El oso", "El bar de Scott Fitzgerald". El título del primero cambia según el soporte: es "Patos salvajes sobre un lago congelado" en N y "Un detective privado" en Babelia. "El bar de Scott Fitzgerald" omite una larga anotación irónica sobre el cálculo financiero de la supervivencia del profesor jubilado de Princeton, que aparece en cambio en los Diarios (III, 275). El estilo de estos textos se acerca al de las "Notas ..." semiensayísticas o claramente ficcionales publicadas en marcos heterogéneos (ver aquí nota 5), cuyos fragmentos, si bien de diverso tono, se pueden agrupar en torno a un tópico central, un motivo literario, etc.

7. Enumero las principales inserciones en la prensa: 1) El libro Fragmentos de un diario (2012) se publica con dibujos de Eduardo Stupía (2012). En esta ocasión, Pablo Gianera (2012) propone una entrevista a ambos autores acompañada con unos pocos fragmentos que se insertarán en el volumen III (255-256; 264-265); 2) "La construcción de la señorita Erika Turner" (2014), aparece como anticipo parcial de "Notas en un diario (1987)", texto que ingresa en la Antología personal (2014). Combina anotaciones contenidas en I (33) y III (195-198), entre otras. En I, 33, una modificación afecta al sujeto (en primera persona en cambio de tercera); 3) "Apuntes de lo que ha sido mi vida" (2015) precede la salida del volumen I de los Diarios y transcribe algunas de sus páginas (175-177; 182), con el agregado de un fragmento final que menciona la copia de los diarios por Renzi, a sus "setenta y tres años"; 4) El fragmento "Nota a la edición" (La Biblioteca n ${ }^{\circ}$ 15, 2015: 125-126), que acompaña la reedición en revista de los ensayos sobre narradores norteamericanos de 1967, enlaza páginas de los Diarios (I, 293; 294; 295) con una actualización a la manera del caso precedente, bajo forma de "Posdata del 2 de mayo de 2015 " (126); 5) "Los libros de mi vida. Páginas de una autobiografía futura" se inserta en un número de homenaje al autor (La Biblioteca $\left.{ }^{\circ} 15,2015\right)$ que aparece pocos meses antes del primer tomo de los Diarios. Coincide literalmente con "En el umbral", el largo capítulo introductorio del tomo I (15-32), salvo por la ausencia de un párrafo que concierne al padre del narrador ("Mi padre [...] esa manía", I, 28), y por la inserción de dos notas al pie que faltan en el volumen (166).

8. Contra toda expectativa previa escéptica o reticente, el diario de Piglia existe y existía en efecto desde siempre. Algunas pruebas visuales de la realidad objetiva de los cuadernos negros aparecieron en fecha reciente: los enfoques en la película de Andrés Di Tella (2015) y fotografías de algunas páginas en la revista La Biblioteca de Buenos Aires (2015: 139, 163, 178).

9. Por supuesto, los Diarios no están exentos de ese tratamiento. Ciertas páginas reproducen fragmentos ya publicados en diarios ficcionales, como la nota Difracción (III, 196), que coincide con la primera mitad de la entrada del mismo nombre en "Diario de un loco" (134), o como el último pasaje de "Private Eye" (III, 253-254), que retoma la entrada "Visión" (153-154) del mismo, con algunas supresiones que no alteran nada de lo esencial. La correspondencia de textos es a su vez literal entre ciertos fragmentos de "En otro país" (Prisión perpetua) que cuentan los orígenes del diario (1988: 14, 13), y el primero de los 
volúmenes publicados (respectivamente: I, 11, con cambio de la enunciación de la primera a la tercera persona, y luego I, 28 y 33 ).

10. “ [L'] œuvre n'est pas des plus grandes, la vie n'a rien d'héroïque [...]; mais la vie se donne à lire comme tout entière dirigée vers la constitution de l'œuvre».(278)

11. Ver en este volumen el artículo de Diego Alonso.

12. O, como lo sostiene acertadamente Martín Kohan (2017), Piglia acerca el relato a la experiencia, pero aleja el relato de él mismo.

13. La crítica ha prestado especial atención a las técnicas de escritura y a los numerosos ejemplos de circulación inter- e intratextual desde sus primeras ocurrencias en el corpus, que desafiaban la sagacidad de los lectores con claves hiperliterarias más o menos secretas. Para el comentario de ejemplos acompañado de un buen recuento bibliográfico, ver Fornet (2007) y González Álvarez (2009).

14. "El nadador" retoma "En noviembre" (Piglia 2006: 152-157), con unas pocas correcciones; "La moneda griega" reescribe "Pequeño proyecto para una ciudad futura", publicado en 2001 (Pron 2015).

15. Para un análisis de este punto y de las recomposiciones de los volúmenes de cuentos, ver Orecchia Havas 2010: 23-29.

16. Se puede recordar un objetivo semejante en el recurso a Renzi en el "Epílogo" de Plata quemada (1997).

17. Piglia recapitula las apariciones de Renzi en su obra e indica que "se trataba de ver si era factible secretamente (sic) la biografía de alguien a lo largo de una serie de relatos, que contaban otras historias pero que de modo paralelo se ocupaban de la vida de Renzi [...], sin que él sea el centro de la trama." (Montiel Figueiras 2003: 2).

18. En Junior se acumulan probablemente rasgos de otros escritores, en particular de Miguel Briante, "el pibe Briante" (1944-1995), amigo de siempre frecuentemente mencionado en los Diarios, que es un poco más joven que Piglia, y que, como él, resultó ganador precoz del concurso de cuentos de El escarabajo de oro en 1962. Como Briante, Junior es periodista.

19. Uno de los primeros textos en que aparece la firma de E. Renzi, poco mencionado en los recuentos bibliográficos, es la traducción de "La estructura significativa", de Lucien Goldmann, en la revista Literatura y sociedad (1965).

En la misma entrevista con Montiel Figueiras ya citada, Piglia separa la figura de Renzi en tanto personaje, del uso del nombre en trabajos críticos: "[Otro] camino es seguir el gesto de Pessoa con sus heterónimos, que a veces me atrae y que reproduciría algunas cosas que ya hice [...]. [Renzi apareció] como responsable de una antología de cuentos policíacos que yo realicé [se refiere a los Cuentos de la Serie negra (1969)], y más tarde firmó notas que me pedían para periódicos y revistas. Es un camino muy tentador, escribir y publicar un libro no con mi nombre sino como Emilio Renzi, para ver qué efecto provoca." (2003: 2. Subrayado mío)

20. En el fondo de papeles de Ricardo Piglia en Princeton (ver también notas 21,23 y 28 y el "Anexo" que cierra este artículo) se encuentra una ficha biográfica dactilografiada en hoja suelta que menciona a los miembros de las ramas paterna y materna (Box B 001158- Folder 5). Allí el apellido Renzi está atribuido a la abuela materna (Albina Renzi); el apellido de la madre sería Maggiori.

21. Ver "Sobre las copias sucesivas del diario en diferentes soportes", primera nota del "Anexo" al final de este artículo.

22. En los Diarios se menciona un gesto semejante en una anotación de agosto de 1970: "Quizá al transcribir estos cuadernos y copiarlos a máquina tendré que decir algo sobre el hueco que se produce en 1962 y hacer entonces el relato del incendio del cuaderno en el piso de hotel en el invierno de 1967; gesto espectacular, vacío, que borraba varios meses de mi vida." (II, 211) 
23. Ver "Sobre discontinuidades de la serie", segunda nota del "Anexo" al final de este artículo.

24. El texto forma parte originariamente del volumen Crónicas de Norteamérica (Jorge Álvarez 1967), que contenía una presentación de cada autor seleccionado. En 2015 se reproducen esos ensayos de presentación en el número de la revista La Biblioteca dedicado a Piglia.

25. La segunda mitad del año 1968 es particularmente rica en menciones a Pavese. Entre otros tópicos, Piglia indica el deseo de escribir un cuento mezclando fragmentos de su diario y del del italiano (II, 70-71), y escribe una nota sobre la técnica de la reticencia en Pavese (II, 98) comparado con Hemingway. Son meses de lectura de las cartas del primero, que alternan con las de literatura norteamericana. Diez años más tarde, en 1979, en un pequeño inventario de sus "novelas fracasadas" incluye "una novela corta centrada en Pavese, que transcurre en Italia y gira sobre los diarios personales" (III, 101).

26. Una variante metonímica del tema se encuentra en la elocución asmática de algunos personajes de los cuentos (Rinaldi, Almada), interrumpida y jadeante, evocadora de las crisis que parecen poner al asmático al borde de la muerte. Se puede recordar que asmáticos son también Pavese y ... Piglia.

27. En otra definición del prisma ficcional, muertos en vida son los que han perdido el amor, como Macedonio en La ciudad ausente: "Muerta Elena, él ya no podía vivir y sin embargo seguía vivo. (Io non morí e non rimasi vivo, así lloraba el Dante.)” (1992: 161).

28. En el "Prólogo" a la edición de 2006, Piglia indica que el cuento fue escrito a principios de 1970 y pasó luego por "diversas versiones y múltiples reescrituras" (14). Sobre este punto ver también "Sobre versiones y reescrituras: "Un pez en el hielo", tercera nota del "Anexo" al final de este artículo.

29. Fragmento de una anotación del 10 de abril de 1949 (Pavese 2007: 367).

30. "El cazador Gracchus" es un texto fragmentario de Kafka, redactado en diferentes momentos entre 1913 y 1922, que cambia en cada reescritura y queda inacabado. Se lo considera dentro de la tradición del tema del holandés errante. El fragmento citado por Piglia dice: "Nadie leerá nunca lo que escribo, nadie vendrá en mi ayuda" (Mi traducción). (Cillaire 2010). Por otra parte, Gracchus es nominalmente evocado en la entrada del 6 de abril de 1917 del Diario de Kafka (1982: 485). El nombre latino "graculus" significa en efecto lo mismo que "kavka" en checo, la corneja (Frank 2010).

Un autor apreciado por Piglia, W.G. Sebald, incluye a su vez en Vertiges (2010: 169-173), un importante pasaje sobre Kafka y Gracchus.

31. La escritura en Pavese "se revela, así, [...], como un quehacer a orillas de la muerte, que lo mantiene vivo al precio de no dejar de pensar en el suicidio como un deber moral." (Matamoro 2000: 83)

32. Sobre Macedonio, González Álvarez (2009: 67) cita esta frase de Piglia: "[L]o que viene después de los prólogos es el diario de un muerto".

33. "No podría volver a escribirlos, sería imposible, son páginas y páginas, pero al leérselos a una muchacha ves otra cosa, parece que estuviéramos espiando la vida de un desconocido que se mueve por la ciudad en círculos, o mejor, que se mueve y va de un lado al otro, perdido por la vida." (I, 354)

34. "Le regard d'Orphée est le don ultime d'Orphée à l'œuvre, don où il la refuse, où il la sacrifie en se portant, par le mouvement démesuré du désir, vers l'origine, et où il se porte, à son insu, vers l'œuvre encore". 
35. El tema del secreto que el diario recela se encuentra narrativizado en "Encuentro en Saint Nazaire" (2000), donde Stevensen lleva un diario con vivencias personales que recela un secreto inextricable para él mismo.

36. “[T] 2003: 34)

37. En esto Pavese aparece como un ejemplo en los años juveniles: “También Pavese tematiza la clave de todos nosotros (o mejor, de algunos, o mejor todavía, sólo de mí), la literatura es lo contrario de la vida y ésa es su virtud." (I, 71) o bien: “Aprender del Pavese de 1935, en pleno confinamiento [...], solo, a la intemperie, en su diario escribe sobre su poesía, sobre su manera de trabajar, nunca se deja ganar por "las tragedias del alma". (76)

38. La fórmula final parece contener además un eco de la famosa frase de Marechal, que se habría jactado de estar escribiendo "una novela genial". (Piglia 1990: 411)

39. "Entonces imaginó su vida sin los cuadernos, sin los cuadernos, subrayó, sin el peso de los registros escritos de lo que hacía, deseaba, pensaba o creía." (III, 161)

40. Sobre Blanco Nocturno, Piglia dice que: "[La novela] está ligada a lo que me sucede cuando leo mi diario y entonces estoy tratando de recuperar no sé si los textos específicos que yo escribía pero sí va a incluir la sensación y los sentimientos que me genera leer parte de mi vida" (Entrevista de Deán Luis Reyes citada por González Álvarez 2009: 151).

\section{RESÚMENES}

El artículo examina la "voluntad de hacer literatura" que revela la edición de Los diarios de Emilio Renzi. Se estudian pautas externas e internas que definen el carácter literario de los Diarios. Las primeras, entre las que se cuentan las prepublicaciones fragmentarias, ponen en discusión la idea de texto(s) póstumo(s). Entre las segundas, se recuerdan las prácticas diversas de reescritura y selección de materiales, se analiza la estructura de los tres volúmenes publicados y el desplazamiento de la voz autoral hacia la de Emilio Renzi. Este último dispositivo se asocia aquí a una mancha temática y a una modulación ficcional de la enunciación literaria que el escritor propone a través de la voz de sujetos que se encuentran al borde de la muerte. Lo imaginario, lo fantasmático y la realidad biográfica convergen así en la operación dominante que literaturiza al diario personal. Los Diarios son el (último) gran viaje de Piglia hacia la creación literaria, un viaje que vuelve a mirar hacia el origen y combate los finales definitivos.

El Anexo al trabajo examina algunos datos complementarios a partir de los archivos de Piglia en Princeton.

L'article se penche sur la "volonté de faire de la littérature" visible dans Los diarios de Emilio Renzi. Á ce propos il examine des caractéristiques externes et internes de los Diarios qui révèlent leur nature littéraire. Les premières, parmi lesquelles se trouvent les prépublications de fragments choisis, permettent de discuter l'idée de texte(s) posthume(s). Parmi les secondes, sont soulignées différentes pratiques de réécriture et sélection de matériaux et sont analysés aussi bien l'architecture des trois volumes publiés que le déplacement de la voix de l'auteur vers celle d'Emilio Renzi. Le travail associe ce dernier dispositif avec une thématique et une modulation fictionnelle de l'énonciation littéraire qui, chez cet écrivain, met en relief la voix d'un sujet au 
bord de la mort. L'imaginaire, le phantasmatique et le biographique convergent ainsi sur cette opération fondamentale à l'heure de rendre le journal personnel à la littérature. Les Diarios sont le (dernier) grand voyage de Piglia vers la création littéraire; c'est un voyage à la fois de révision de son origine et de lutte contre une quelconque clôture définitive.

En Annexe à l'article sont examinées quelques données qui procèdent des archives de Piglia à Princeton.

This article analyzes the "will of literature" visible in Los diarios de Emilio Renzi. On that purpose, it discusses the external and internal evidence which reveal the literary nature of the Diarios, beginning by the chronology of the editing and the previous partial publications of texts; this leads to some adjustements of the notion of "posthumous" (work). On the field of internal evidence, the essay comments Piglia's practices of rewriting and focuses on the structure of the three volumes as well as on the transfer from the author's voice to Emilio Renzi's one. This last device is associated here with some of Piglia's themes and with his fictional images of literary voices being in a frontier between life and death. Imaginary, phantasmatic and biographical elements coincide then in this main strategy to make the diary a litterary masterpiece. The Diarios are the (last) great Piglia's travel to literary creation; it looks again towards the origins and fights against the idea of definite ends.

The Annexe section examines some data recovered in Piglia's files of Princeton University.

\section{ÍNDICE}

Palabras claves: lo póstumo, diarios, estrategias de composición, enunciación desde el limes, escritura interminable

Mots-clés: (œuvre) posthume, journaux intimes, stratégies de composition, énonciation dans le limes, écriture interminable

Keywords: posthumous (work), personal diaries, literary strategies, énonciation on the limes, endless writing

\section{AUTOR}

\section{TERESA ORECCHIA HAVAS}

Université de Caen

orecchia-havas@wanadoo.fr 